\title{
Identity Crisis: An Integrative Re-Evaluation of Typhlatya Shrimp within the Karst Aquifer of the Yucatán Peninsula, Mexico.
}

\section{Lauren Ballou}

Texas A\&M University at Galveston

\section{David Brankovits}

Texas A\&M University at Galveston

\section{Efraín M. Chávez-Solís}

Universidad Autónoma de Baja California - Ensenada

Brett C. Gonzalez

National Museum of Natural History

Shari Rohret

Woods Hole Oceanographic Institution

\section{Alexa Salinas}

University of Notre Dame

Arielle Liu

University of Arizona

\section{Nuno Simões}

Universidad Nacional Autónoma de México, Sisal

\section{Fernando Alvarez}

Universidad Autónoma del Estado de México

\section{Maria Pia Miglietta}

Texas A\&M University at Galveston

Thomas M. Iliffe

Texas A\&M University at Galveston

Elizabeth Borda ( $\square$ eborda@tamusa.edu )

Texas A\&M University-San Antonio

\section{Research Article}

Keywords: Typhlatya, T. pearsei, T. mitchelli

Posted Date: September 29th, 2021

DOI: https://doi.org/10.21203/rs.3.rs-926828/v1 
License: (c) (i) This work is licensed under a Creative Commons Attribution 4.0 International License. Read Full License 
1 Identity Crisis: An integrative re-evaluation of Typhlatya shrimp within the karst aquifer of

2 the Yucatán Peninsula, Mexico.

3

4 Lauren Ballou, David Brankovits, Efraín M. Chávez-Solís, Brett C. Gonzalez, Shari Rohret,

5 Alexa Salinas, Arielle Liu, Nuno Simões, Fernando Alvarez, Maria Pia Miglietta, Thomas M.

6 Iliffe, and Elizabeth Borda

7

8 Author Information

9 Affiliations

10 Department of Marine Biology, Texas A\&M University at Galveston, 200 Seawolf Pkwy,

11 Galveston, TX, USA

12 Lauren Ballou, Maria Pia Miglietta \& Thomas M. Iliffe

13 Department of Marine and Coastal Environmental Science, Texas A\&M University at

14 Galveston, 200 Seawolf Parkway, TX, USA

15 David Brankovits

16 Posgrado en Ciencias Biológicas, Unidad de Posgrado, Edificio A, 1er piso, Circuito de

17 Posgrados, Ciudad Universitaria, Coyoacán, Ciudad de México, Mexico

18 Efraín M. Chávez-Solís

19 Instituto de Investigaciones Oceanológicas, Universidad Autónoma de Baja California,

20 Ensenada, Baja California, Mexico

21 Efraín M. Chávez-Solís

22 Department of Invertebrate Zoology, Smithsonian Institution, National Museum of Natural

23 History, P.O. Box 37012, Washington D.C., USA

24 Brett C. Gonzalez 
Department of Earth, Atmospheric and Planetary Sciences, Massachusetts Institute of

26 Technology, Green Bldg., 77 Massachusetts Ave, Cambridge, MA, USA

27 Shari Rohret

28 Geology \& Geophysics Department, Woods Hole Oceanographic Institution, 266 Woods

Hole Road, MS \#52, Woods Hole, MA, USA

30 Shari Rohret

Department of Biological Sciences, University of Notre Dame, 100 Galvin Life Science

Center, Notre Dame, IN, USA

33 Alexa Salinas

School of Anthropology, University of Arizona, Emil W. Haury Anthropology Bldg., 1009

E South Campus Dr., Tucson, AZ, USA

Arielle Liu

37 Unidad Multidisciplinaria de Docencia e Investigación, Facultad de Ciencias, Universidad Nacional Autónoma de México, Puerto de Abrigo S/N, Sisal, Yucatán, Mexico Nuno Simões

40 National Coastal Resilience Laboratory (LANRESC), Puerto de Abrigo S/N, Sisal,

41 Yucatán, Mexico

42 Nuno Simões

International Chair for Ocean and Coastal Studies in Mexico, Harte Research Institute,

44 Texas A\&M at Corpus Christi, 6300 Ocean Drive, Corpus Christi, TX, USA

45 Nuno Simões

Colección Nacional de Crustáceos, Dpto. de Zoología, Instituto de Biología, UNAM. Tercer

47 circuito s/n, Ciudad Universitaria, Copilco, Coyoacán, A.P. 70-153, México D.F., Mexico 
Fernando Alvarez

Department of Life Sciences, Texas A\&M University San Antonio, One University Way,

San Antonio, TX, USA

51 Elizabeth Borda

52

53 Corresponding Author

Correspondence to Elizabeth Borda

eborda@tamusa.edu

\section{ABSTRACT}

The Yucatán Peninsula, Mexico is a carbonate platform well-known for extensive karst networks of densely stratified aquifer ecosystems. This aquifer supports diverse anchialine fauna, including 60 species of the globally distributed atyid shrimp genus Typhlatya. Four species (T. campecheae, T. pearsei, T. dzilamensis and T. mitchelli) are endemic to the Peninsula, of which three are federally

62 listed in Mexico. This first integrative evaluation [i.e., molecular (public and newly generated),

63 morphological, broad geographic and type locality sampling, and environmental data] of Yucatán

64 Typhlatya reveals considerable species identity conflict in prior phylogenetic assessments, broad 65 species ranges and sympatry within cave systems, five genetic lineages (three known and two new 66 to science) with the endangered T. campecheae herein classified as junior synonym of the 67 vulnerable T. pearsei. Ancestral/divergence reconstructions support convergent evolution of a 68 low-salinity/stenohaline ancestor of a post-Paleogene arc Yucatán+Cuba Typhlatya clade within a 69 euryhaline/anchialine-adapted atyid clade, and secondary adaptation of the coastal-restricted euryhaline [2-37 psu] Typhlatya dzilamensis (unknown conservation status), of which the

71 remaining four species lineages are low-salinity/stenohaline adapted found in both inland and 72 coastal regions. This study demonstrates the need for integrative/interdisciplinary approaches 73 when conducting biodiversity assessments in complex and poorly studied aquifers. 
75 The Yucatán Peninsula, Mexico consists of an emerged carbonate platform spanning 165,000 km² 76 that contains extensive karst aquifer ecosystems ${ }^{1}$ with networks of inland and coastal caves, known

77 as cenotes, the local term for sinkhole ${ }^{2-4}$. The Peninsula's unconfined aquifer has density 78 stratification where marine origin saline groundwater mixes with the meteoric lens ${ }^{5-8}$. 79 Consequently, the flooded caves are characterized by meromictic conditions with well-defined haloclines that occur progressively deeper from coastal to inland regions ${ }^{4,7,9,10}$ Inland caves (Figure

81 1) are generally deep pit-style formations formed via collapse, whereas coastal caves are typically

82 shallower and branch into extensive anastomotic networks ${ }^{3,10}$. Biogeochemical cycling associated

83 with the haloclines have a vital role in sustaining the subterranean food web ${ }^{11}$. Collectively, the 84 spatial variability in salinity and hydrogeology creates a collection of coastal subterranean 85 estuaries $^{5,12}$ that host a diverse array of characteristic stygobitic (cave-adapted) fauna ${ }^{13-15}$. These 86 environments and associated fauna are also widely referred to as anchialine $e^{16-18}$. How these spatial 87 variables shape the biodiversity and evolution of anchialine fauna remains poorly understood.

More than 170 anchialine species have been recorded in the Yucatán Peninsula, the majority of which are crustaceans ${ }^{13-15,19}$. Species of the atyid shrimp genus Typhlatya Creaser, 1936 (Atyidae De Haan, 1849 [in De Haan, 1833-1850]) were among the first cave fauna described from the Yucatán Peninsula ${ }^{20}$. The genus consists of 17 species and exhibits a globally disjunct distribution within anchialine habitats: Yucatán Peninsula, Caribbean (Puerto Rico, Dominican Republic, Lesser Antilles, Netherlands Antilles, Columbia, Honduras), West Indies (Bahamas, Turks and Caicos), Bermuda, Ascension Island, Mediterranean (France, Spain), and the Galapagos Islands; with one undescribed species from Zanzibar ${ }^{21,22}$. The placement of Typhlatya arfeae Jaume \& Bréhier, 2005, Typhlatya galapagensis Monod \& Cals, 1970, Typhlatya miravetensis Sanz \& 
97 Platvoet, 1995, and Typhlatya monae Chace, 1954 within Typhlatya is debated, as recent phylogenetic work suggests these species are more closely related to Antecaridina Edmondson, 1954, Halocaridina Holthuis, 1963, Stygiocaris Holthuis, 1960, and/or Typhlopatsa Holthuis, 1956; resulting in the paraphyly of Typhlaty $a^{21,22}$.

To date, four species of Typhlatya have been described from the Yucatán Peninsula: Typhlatya pearsei Creaser, 1936, Typhlatya campecheae H.H. Hobbs III \& H.H. Hobbs Jr., 1976, Typhlatya mitchelli H.H. Hobbs III \& H.H. Hobbs Jr., 1976, and Typhlatya dzilamensis Alvarez, Iliffe \& Villalobos, 2005. Three of the four species are federally listed as vulnerable (T. pearsei, $T$. mitchelli) or endangered (T. campecheae) to extinction ${ }^{23}$. Traditional species descriptions primarily utilized morphological differentiation, illustrations, and locality data as diagnostic ${ }^{20,24,25}$. While each species is currently accepted as morphologically distinguishable (Figure 2), character variability has been reported in the case of $T$. pearse $i^{26}$. Because these records came from a time before molecular techniques were easily accessible and widely used as standard practice, no molecular data is available for type species. The lack of molecular data from type material, the potential for cryptic speciation, and variable morphology poses challenges in consistent identifications of subterranean crustacean species ${ }^{27-29}$.

In recent years, many studies have sought to understand the evolutionary history and relationships within Typhlatya and its closest relatives ${ }^{21,22,29-34}$. These investigations have produced useful genetic data (mitochondrial and nuclear genes) for Yucatán Peninsula Typhlatya species and made available via GenBank ${ }^{35}$. However, it is not uncommon to find that publicly available sequences have erroneous identifications leading to taxonomic and systematic confusion ${ }^{36-40}$. What prompted the current study was an evaluation of data from previous work revealed conflicting species identifications and incongruent phylogenetic hypothesis ${ }^{21,22,29-34}$. Therefore, the objective of this 
120 study was to conduct the first integrative biodiversity assessment within the poorly studied karst

121 aquifer of the Yucatán Peninsula, through the evaluation of molecular (published and newly

122 sequenced), morphological, broad geographic and key type localities, and environmental/salinity

123 data, to clarify species identities and evaluate the evolution and biogeographic history of the

124 Yucatán clade.

\section{RESULTS}

126 The phylogenetic/genotypic relationships of Typhlatya specimens were inferred from 16S rRNA 127 (16S; 74 sequences, 515 bp), Cytochrome c oxidase subunit I (COI; 32 sequences, 1,233 bp), 128 Cytochrome b (CYTB; 50 sequences, 588 bp), 18S rRNA (18S; 15 sequences, 1,779 bp), 28S 129 rRNA (28S; 21 sequences, 1,090 bp) and Histone 3 (H3, 21 sequences, 327 bp). Maximum 130 Likelihood (ML) and Bayesian Inference (BI) reconstructions based a concatenated multi-gene 131 (select 16S, COI, CYTB, 18S, 28S and H3; 17 sequences, 5,514 bp) dataset supported two main 132 clades and five genetic lineages (Figures 3A), represented by T. pearsei, T. mitchelli, T. 133 dzilamensis, and two unknown lineages, hereafter, referred to as Typhlatya sp. A and Typhlatya 134 sp. B; details below. Inter-clade genetic uncorrected pairwise (p)-distances of 16S and COI, ranged $135 \quad 5.40-18.1 \%$ and $10.0-19.5 \%$, respectively. Intra-clade uncorrected p-distances were highest in 136 COI for T. dzilamensis (1.7\%) and in $16 \mathrm{~S}$ for Typhlatya sp. A (1.0\%), and less than $1 \%$ for 137 remaining clades in both genes. See STable1 for summary of intra- and inter-clade uncorrected p138 distances.

$140 \mathrm{ML}$ and BI analyses of six concatenated genes (16S, COI, CYTB, 28S, 18S, H3) recovered two 141 main clades within Typhlatya, each with fully supported subclades (ML Bootstrap, BS 100; 
142 Bayesian Posterior Probability, BPP 1), and non-conflicting topologies between analyses: Clade I,

143 Typhlatya sp. A + (T. mitchelli + T. pearsei $)$ and Clade II, T. dzilamensis + Typhlatya sp. B, 144 respectively (Figure 3A). Individuals (C1-3; n=3) sampled from the type locality of T. campecheae 145 (Grutas de Xtacumbilxunam, Campeche State (CS)) were recovered within the T. pearsei clade. 146 Typhlatya sp. A was represented by individuals sampled from Cenotes Nah-Yah (Yucatán State 147 (YS); $\mathrm{n}=1$ ) and Kankirixche (YS; $\mathrm{n}=1$ ) and recovered as sister to T. pearsei + T. mitchelli. 148 Typhlatya sp. B sampled from Cenote Hoctún (YS; n=1) was recovered as sister to T. dzilamensis. 149 The Typhlatya dzilamensis clade was comprised of an individual (E4553) from the type locality 150 (Dzilam de Bravo, YS) of this species, as well as individuals ( $\mathrm{n}=3$ ) from Cenotes Actun Ha 151 (Quintana Roo State, QRS), Sabtun 1 (YS), and X'tabay (YS). All other species locales are 152 provided in STable 2.

$153 \mathrm{ML}$ and BI analyses of $16 \mathrm{~S}$ recovered congruent topologies to the multi-gene hypothesis, except 154 for the outgroup taxon T. garciai, placing as sister to Clade II (T. dzilamensis + Typhlatya sp. B) 155 in the BI analysis, however, with low support (BPP 0.67). Like the multi-gene phylogeny (Figure 156 3B), two main clades were recovered: Clade I (BS 85, BPP 0.99), Typhlatya sp. A + (T. mitchelli $157+$ T. pearsei; BS 70, BPP 0.98), and Clade II (BS 97, BPP 1), T. dzilamensis + Typhlatya sp. B.

158 Single-gene analyses of 28S, COI, and H3 recovered congruent topologies with the multi-gene 159 hypothesis, although Typhlatya sp. B was absent from 28S and H3 analyses (SFigures 1-3). Genes $16018 \mathrm{~S}$ and CYTB recovered incongruent topologies, with Typhlatya sp. A absent from 18S analyses 161 (SFigures 1-3). 
164 The phylogenetic hypothesis resulting from the analysis of $16 \mathrm{~S}$ (Figure 3B), including published 165 and newly sequenced data, was incongruent with previous hypotheses and presented conflicts in 166 species identification, except for Botello et al. ${ }^{21}$ (in part); see Figure 3C and STable 3. GenBank 167 sequences identified as T. mitchelli $(\mathrm{n}=19)$ were consistent, except for one $\left(\mathrm{KX} 844712^{22}\right)$, which 168 was recovered here as Typhlatya $\mathrm{sp}$. B. GenBank sequences attributed to $T$. pearsei $(\mathrm{n}=6)$ were 169 consistent in identity, except for three sequences (AY115537-AY115539 ${ }^{30,34}$ ), which instead were 170 nested within the T. dzilamensis clade. GenBank sequences identified as Typhlatya sp. $(\mathrm{n}=7)$ were 171 recovered (and revised) as followed: T. mitchelli clade, FN995395¹; T. pearsei clade, AY115540172 AY115544 ${ }^{30,34}$; and T. dzilamensis clade, FN995396 ${ }^{31}$. Lastly, individuals sampled from the type 173 locality of $T$. campecheae (Grutas de Xtacumbilxunam; n=3) were recovered within the T. pearsei 174 clade, while individuals sampled from the type locality (previously ${ }^{21,22}$ and in this study) of $T$. 175 dzilamensis (Dzilam de Bravo; $\mathrm{n}=5$ ) were recovered within the $T$. dzilamensis clade.

176 Single gene (i.e., 18S, 28S, COI, CYTB, H3) analyses (SFigures 1-3) resulted in similar 177 identification conflicts as noted above, except for 18S. In total, five misidentifications were 178 uncovered from GenBank data (summarized in Figure 3C, STable 3): i) Typhlatya sp. (sensu 179 Hunter et al. ${ }^{30}-\mathrm{CYTB}, 16 \mathrm{~S}$ ), here recovered as T. pearsei; ii) T. pearsei (sensu Hunter et al. ${ }^{30}-$ 180 CYTB, COI, 16S; Zakšek et al. $\left.{ }^{29}-28 \mathrm{~S}\right)$, here recovered as T. dzilamensis; iii) Typhlatya sp. (sensu 181 von Rintelen et al. ${ }^{31}-16 \mathrm{~S}, \mathrm{H} 3,28 \mathrm{~S}$ ), here recovered as T. mitchelli; iv) Typhlatya sp. (sensu von 182 Rintelen et al. ${ }^{31}-16 \mathrm{~S}, \mathrm{H} 3,28 \mathrm{~S}$ ), here recovered as T. dzilamensis; and v) T. mitchelli (sensu Jurado183 Rivera et al. ${ }^{22}-$ CYTB, COI, 16S), here recovered as Typhlatya sp. B. Each clade showed 184 conflicting identities, but the highest number was found for T. dzilamensis and T. pearsei. 
186 Evaluation of the genetic identities of Typhlatya specimens using $16 \mathrm{~S}$ and multi-gene phylogenetic

187

188

189

190

191

192

193

194

195

196

197

198

199

200

201

202

203

204

205

206

207 approaches supported broad ranges for each of the five identified species lineages among cenotes. A total of 85 Typhlatya individuals were observed within 30 inland and coastal cenotes from variable salinities [0.5 - 37 practical salinity unit, psu; STable 2], here also including reassigned GenBank sequence data (Figure 4, STables 3). Typhlatya mitchelli $(\mathrm{n}=34 ;$ cenotes $=12)$ was observed inland (YS), as well as in coastal cenotes (QRS). This species was sampled from 'low salinity' waters [<4.99 psu], above the halocline, within Cenotes Jailhouse [2.9 psu; OBH, QRS] and Tza Itza [0.63 psu; YS]. Typhlatya pearsei $(\mathrm{n}=14$; cenotes=7) was found inland (YS, CS) and in coastal (QRS) cenotes. This species was sampled from 'low salinity' waters, above the halocline, within Cenotes Jailhouse [3.5 psu; OBH, QRS] and Noh-Mozon [0.7 psu; YS], and the type locality of $T$. campecheae (Grutas de Xtacumbilxunam, CS). Typhlatya dzilamensis $(\mathrm{n}=30$; cenotes $=11)$ was observed in the north/north-western coastal YS and QRS cenotes, spanning $\sim 500$ km. This species was recorded from Cenote Sabtun 1 (YS) and Cenote Santa Maria (YS), with the greatest distance from the coastline of $\sim 17-18 \mathrm{~km}$ inland. Typhlatya dzilamensis was the only species sampled from both 'low salinity' and 'high salinity' [ $>5 \mathrm{psu}$ ] waters [ranging 2-37 psu], above and below halocline(s). Within the OBH system (QRS), T. dzilamensis was observed from multiple salinities, above [2-4 psu] and below halocline(s) [33 psu], while in Cenote Crustacea (QRS), below multiple haloclines, ranging 13-34 psu. Typhlatya sp. A ( $\mathrm{n}=4$; cenotes $=3)$ was observed within inland (Kankirixche and Nah-Yah, YS) and coastal [Bang, 2.5 psu; OBH, QRS] cenotes, sampled oligohaline waters, above the halocline. Typhlatya $\mathrm{sp}$. B $(\mathrm{n}=3$; cenotes $=3)$ was also found within inland (Cenote Hoctun, YS) and coastal [4.4 psu; Na'ach Wennen Ha, OBH, QRS; and Bang, OBH, QRS] systems, sampled from low salinity waters, above the halocline. 
208 Representatives of all five lineages were collected from the OBH cave system in waters of varying 209 salinity (Figure 4). Specifically, species were collected sympatrically from Cenotes Bang 210 (Typhlatya sp. A, Typhlatya sp. B, T. dzilamensis; $\sim 2$ psu), Jailhouse (T. mitchelli, T. pearsei; $>3$

211 psu), and Na'ach Wennen Ha (Typhlatya sp. B, T. dzilamensis; $\sim 4$ psu), respectively. Typhlatya 212 species also occurred sympatrically within Cenotes Actun Ha (T. dzilamensis, T. mitchelli; Tulum, 213 QRS), Hoctún (Typhlatya sp. B, T. mitchelli; Hoctún, YS), and Sistema Paamul (T. mitchelli, T. 214 pearsei; Paamul, QRS;), respectively (Figure 4).

215 Morphology

216 Typhlatya species were examined using the key developed by Alvarez et al. ${ }^{25}$ (Figure 2; SFigure 217 4). Typhlatya pearsei and T. campecheae were primarily distinguished by the length of their 218 rostrum relative to antennular segments ${ }^{25}$; however, both $T$. pearsei and individuals from the type 219 locality of $T$. campecheae exhibit a variable rostrum length extending past the eyestalk and 220 extending towards the end of the first or midway to the second antennular segment (SFigure 4 A, 221 B). The rostrum was found to be shorter than the eyestalk in T. mitchelli, whereas the rostrum of 222 T. dzilamensis extends to and just beyond the eyestalk. The rostrum curves upward in T. mitchelli, 223 but not in T. dzilamensis, consistent with species comparisons by Alvarez et al. ${ }^{25}$. Like T. mitchelli, 224 the rostrum of Typhlatya sp. A does not extend beyond the eyes; however, is distinct in that it 225 appears less robust and flatter than the former. Typhlatya sp. B was not available for morphological 226 evaluation. A provisional key based on genetic identification and morphological evaluation 227 stemming from this study (and thus here excludes $T$. campecheae, see details in Discussion) can 228 be found in Supplementary Information. 
232 Divergence dating estimates based on a relaxed molecular clock (4 partitions: COI+CYTB, 16S, 233 28S+18S, H3; Calibrated Yule Model; Mean Log Likelihood = -50544.7; see Figure 5; Table 1; 234 STable 4) and four geological events as calibration points, recovered the genus Typhlatya 235 paraphyletic, with the Yucatán clade [18-39 Mya] falling within a Cenozoic clade [33-69 Mya]. 236 The Cenozoic clade was comprised of Typhlatya species from Zanzibar, Ascension Island, 237 Bermuda, Cuba, and Yucatán Peninsula. Alternatively, SFigure 5 shows Typhlatya garciai from 238 Caicos Islands is included within the Cenozoic clade, but excluded in the primary analysis due to 239 limited/missing data. The main Yucatán clades (I and II) were each estimated to have diverged 240 10-25 Mya (Clade I, T. mitchelli, T. pearsei, Typhlatya sp. A) and 8-25 Mya (Clade II, T. 241 dzilamensis, Typhlatya sp. B), respectively. Typhlatya mitchelli + T. pearsei were estimated to 242 have diverged 4-15 Mya. A Cuban clade comprised of T. garciai $+(T$. consobrina + T. taina $)$, and 243 recovered as sister to the Yucatán clade, with an estimated divergence of 24-49 Mya, with the 244 subclade T. consobrina + T. taina diverging 5-7 Mya. Sister to the Cuba + Yucatán clade, were $T$. 245 rogersi + T. iliffei [2-11 Mya] from Ascension Island and Bermuda, respectively, and diverging 246 32-64 Mya. Typhlatya sp. from Zanzibar was the first diverging lineage of the Cenozoic clade.

247 Results of alternative partition schemes, clock models and comparison to divergence estimates 248 from previous work $^{22,23}$ are also summarized in STable 4B.

249 Sister to the Cenozoic clade included the geographically disjunct members of the Typhlatya / 250 Stygiocaris / Typhlopatsa (TST) complex (sensu Sanz and Platvoet ${ }^{41}$; 35-72 Mya): T. miraventsis 251 (Spain) + T. arfeae (France) [4-20 Mya], sister to a clade [29-67 Mya] including T. monae 252 (Dominican Republic) + (Typhlopatsa pauliani (Madagascar; 15-43 Mya) + Stygiocaris 
253 (Australia; 8-10 Mya). The phylogeny also recovered T. galapagensis (Santa Cruz + Isabella

254 Islands; 5-12 Mya) as sister group to the TST clade [48-96 Mya], albeit with low support. The 255 outgroup Halocaridinides + Halocaridina (Hawaii; 3 Mya) were poorly supported as sister taxa 256 (30-90 Mya).

257 Within stochastic mapping, neither equal nor unequal rates models were found to be more optimal 258 (AIC values 27.1 and 27.9, respectively) and therefore the simplest model (equal) was selected. 259 Within the TST clade, seven of the 17 lineages are found within high salinity waters (red lineages). 260 The high salinity lineages are interspersed throughout the TST clade, suggesting that multiple 261 salinity transitions have occurred, although the deeper ancestral nodes within the clade remain 262 unresolved. However, Stygiocaris spp. and the Yucatán+Cuba clade were each recovered with 263 high posterior probability of low salinity/stenohaline ancestors. An independent salinity transition 264 (i.e., Typhlatya dzilamensis, low to high salinity/euryhaline) was recovered within the 265 Yucatán+Cuba clade.

\section{DISCUSSION}

269 This study is the first to phylogenetically evaluate both previously published sequences and newly sequenced data across six mitochondrial and nuclear genes, along with morphological, locality,

271 and salinity data, for Typhlatya species sampled across the Yucatán Peninsula. Previous studies

272 collected new molecular data without evaluating previously published data in their assessments,

273 resulting in phylogenetic and taxonomic conflict ${ }^{21,22,31}$. A major source of confusion stemmed from

274 the identification of $T$. pearsei and T. dzilamensis, given the assumed broad distribution of $T$. 
275 pearsei (also recently reported from fresh and saline waters ${ }^{15}$ ) and the unknown salinity tolerances 276 of $T$. dzilamensis. Studies that correctly identified T. dzilamensis were sampled from the type 277 locality, Dzilam de Bravo (YS) ${ }^{21,22}$. In contrast, $T$. dzilamensis specimens misidentified as $T$. 278 pearsei or Typhlatya sp. were sampled from cenotes outside of the type locality (Dzilam de Bravo) 279 and where salinities were not reported ${ }^{29-31}$. The Dzilam de Bravo system is one of the few 280 scientifically documented cave system in the northern coastline (YS) $)^{13-15,25}$, contrasting the more 281 than $1,000 \mathrm{~km}^{2}$ of coastal cave passages that have been explored and documented along the 282 northeastern edge of the Peninsula (QRS) $)^{15,42,43}$. Because of the distance between these coastal 283 systems $(>200 \mathrm{~km})$, previous work may not have considered the presence of $T$. dzilamensis in 284 regions well outside of its previously known range or euryhaline tendencies, leading to 285 identification errors. However, recent reports ${ }^{43}$ and this study, confirms $T$. dzilamensis as a salinity 286 generalist able to traverse a vast range of salinities [2-37 psu], bringing caution to species 287 identification solely based upon cave locality and/or sampling environment ${ }^{44}$.

288 Traditional taxonomy of Typhlatya species within the Yucatán Peninsula used rostrum length 289 relative to the margin of the eyes, as a critical diagnostic character (Figure 2) ${ }^{24,25,41}$. Rostrum length 290 is a defining character distinguishing $T$. campecheae and $T$. pearse ${ }^{25}$, both with a rostrum reaching 291 beyond the margin of the eyes. In the original description ${ }^{20}, T$. pearsei is described as having a 292 "short" rostrum. However, the redescription ${ }^{24}$ reports variable rostrum length, with the rostrum 293 extending beyond the first antennular segment of the peduncle (proximal base of antennule) 294 somewhere between halfway through the second or just beyond the third antennular segment. This 295 variability was based upon locality, as specimens collected from re-designated type localities Gruta 296 de Chac (YS), Cenote de Hoctún (YS), and Cenote Abejas (QRS) ${ }^{24}$ were reported to have a more 297 extended rostrum than other locales. In contrast, T. campecheae is only known from the type 
298 locality, Grutas de Xtacumbilxunam (CS), and reported with a rostrum length reaching halfway or 299 through the first antennular segment of the peduncle ${ }^{24,25}$. Within this study, the inclusion of 300 individuals sampled from Grutas de Xtacumbilxunam were genetically recovered within the $T$. 301 pearsei clade (Figure 3A) and were not distinguishable by rostrum length from $T$. pearsei (both 302 exhibited rostral length to the first segment and beyond) (SFigure $4 \mathrm{~A}, \mathrm{~B}$ ). Therefore, $T$. 303 campecheae is identified as a phenotypic variant of $T$. pearsei and should be considered a junior 304 synonym, given taxonomic priority ${ }^{20}$. Variation of rostrum length within species has been reported 305 in other members of Decapoda, such as the stygobitic genus Troglocaris or species Aristeus 306 antennatus $^{45-46}$. The type locality of T. pearsei, Cenote Balankanché (X Calakoop, YS), is a 307 restricted access archaeological site and tourist attraction, thus specimens were not available for 308 additional comparisons. A combined morphological and molecular investigation of $T$. pearsei will 309 be needed to properly address this issue.

310 In addition to clarifying the identity of known species within the Yucatán Peninsula, two genetic 311 lineages were newly revealed in our analyses, adding to the current taxonomic complexity (Figure 3123 A-B). Typhlatya sp. A was recovered as sister to T. mitchelli + T. pearsei and was not recovered 313 among GenBank data (Figure 3). Like T. mitchelli, Typhlatya sp. A has a short rostrum that does 314 not extend beyond the margin of the eyes. However, the distal edge of the rostrum of Typhlatya 315 sp. A appears thinner and less robust than that of T. mitchelli (SFigure 4 C, E). Typhlatya sp. B 316 was recovered as sister to $T$. dzilamensis, with one sequence previously misidentified as $T$. 317 mitchelli $\left(\mathrm{KX} 844712^{22}\right)$. Unfortunately, voucher material for Typhlatya sp. B was not available for 318 morphological evaluation, as subsampled specimens were used for molecular analyses. It should 319 be noted that these new lineages came to light post-genetic evaluation and based on few samples $320 \quad(n \leq 4$ each $)$. 
321 Another unexpected result was the sympatry among all five lineages within low salinity waters

322 within the OBH system. Other caves also harbored at least two species (i.e., Actun Ha, Hoctún,

323 Sistema Paamul). Thus, caution should be applied to species identification based upon morphology

324 and salinity preferences alone.

\section{Salinity Tolerance of Anchialine Atyidae}

326 Atyidae is a diverse, globally distributed family of predominantly freshwater shrimp species that

327 includes several independent clades of stygobitic taxa, and at least one identified as anchialine ${ }^{31,48}$.

328 So far, atyid species have not been reported from ocean environments ${ }^{31,48}$. The adaptation for

329 increased salinity tolerance is found across multiple lineages within the anchialine clade comprised

330 of Halocaridinides + Halocaridina + TST complex ${ }^{22,31,41}$. While the reconstruction of ancestral

331 salinity preferences for this anchialine clade (and the TST complex within) was unresolved, the

332 ancestor of the Yucatán+Cuba clade was recovered as having a low salinity preference. All

333 descendants within the clade inhabit low salinity environments, except for euryhaline $T$.

334 dzilamensis, suggesting that T. dzilamensis historically transitioned from low to high salinity.

335 Typhlatya garciai was originally reported as a freshwater species from $\mathrm{Cuba}^{49}$; however, later

336 recorded from brackish/saline cave waters of Caicos Islands ${ }^{50}$. Representatives of T. garciai from

337 both locations were not recovered as monophyletic in our analyses, and the inclusion of T. garciai

338 from Caicos in the supplemental ancestral reconstruction (SFigure 5) also recovered a single

339 transition (T. dzilamensis) to a low salinity ancestor for the Yucatán+Cuba clade.

340 Understanding the evolution of salinity tolerance within anchialine fauna is critical regarding

341 historic sea-level change. Sea-level fluctuations impact underlying aquifers, where

342 micropaleontological observations of benthic meiofauna drastically change with hydrogeology

343 (e.g., fresh $\leftrightarrow$ anchialine $\leftrightarrow$ marine) over time ${ }^{16,51-54}$. Depending upon the salinity tolerance of an 
344 anchialine species, sea-level fluctuation can likely result in significant changes to its respective

345 range and distribution ${ }^{54}$. Subsequently, periods of isolation and expansion within a karst aquifer

346 the may potentially acting as a driver of diversification within anchialine fauna.

347 Evolution within crevicular spaces

348 How anchialine fauna have achieved such disjunct distribution patterns despite inhabiting 349 seemingly isolated environments remains a significant biogeographical question. Typhlatya 350 species are interspersed throughout the Caribbean, West Indies, Bermuda, Yucatán Peninsula and 351 in the West Atlantic ${ }^{21,22}$. However, the Yucatán Peninsula is of particular interest, as it hosts the 352 greatest known diversity (five lineages) of Typhlatya in the world. Previous divergence estimates 353 for the split of the Yucatán clade from the Cuban clade has ranged considerably, 14-27 $\mathrm{Mya}^{21}$ to 354 over $74 \mathrm{Mya}^{22}$ (Table 1; STable 4). In the present study, this split was estimated to be 23-49 Mya 355 (Figure 5; Table 1; STable 4). The disparate age ranges at this node are likely due to the use of 356 different time-calibrations in the molecular clock analyses, data types (mitochondrial genomes vs. 357 gene fragments) and inclusion of different taxonomic representatives. The present study and 358 Botello et al. ${ }^{21}$ utilized recent biogeographic events, while Jurado-Rivera et al. ${ }^{22}$ prioritized deep 359 fossil calibrations outside the anchialine atyid clade. Therefore, the discussion below is in 360 consideration of the findings of the current study.

361 The Yucatán Peninsula and the Paleogene Arc (Cuba+Hispaniola) are hypothesized to have been 362 connected via a land span in the Paleocene through Middle Eocene (until $\sim 49$ Mya) and 363 subsequently split after the formation of the Cayman Trough ${ }^{55-57}$. What has been termed the 364 "Paleogene arc drift vicariance scenario" may explain the disjunct distribution patterns of modern365 day taxa, such as those of certain fish $(\text { Cichlidae })^{57}$. This vicariant event may coincide with 366 divergence times estimated for the split of the Yucatán+Cuba clade [24-49 Mya]. Typhlatya 
367 species (and anchialine atyids) have not been reported outside of groundwater aquifers, and yet open ocean dispersal to isolated oceanic islands (e.g., Bermuda) has been proposed ${ }^{30,58}$. In contrast,

369 this study suggests that dispersal opportunities via spelean corridors through established (or 370 temporary) tectonic and/or volcanic connections are plausible $30,59,60$ and likely dependent on the 371 availability of suitable anchialine habitat and influenced by historic sea-level change ${ }^{16,51-54}$. 372 Therefore, the low salinity/stenohaline ancestor, as proposed here, of Yucatán+Cuba Typhlatya 373 may have migrated along the Paleogene arc via spelean corridors established between Cuba ${ }^{61}$ and 374 emerged portions of the Yucatán Peninsula ${ }^{62}$, and where the meteoric lens would have expanded 375 during periods of low sea-level ${ }^{16,51-54}$ until the eventual split of these landmasses post formation 376 of the Cayman Trough.

377 The Yucatán platform was predominantly submerged during the Cretaceous, with global sea-level 378 oscillations leading periods of partial submergence and emergence since its formation ${ }^{51-54,61-63}$. 379 The ancestor of the Yucatán clade likely invaded an area that was not the fully emerged Peninsula 380 observed today. Rather, depending on the time of colonization, the ancestor could have potentially 381 found suitable anchialine karst habitat along historic coastlines, such as the southern Yucatán 382 Peninsula. The high concentration of inland cenotes northeast of the La Libertad arch (CS) ${ }^{1}$, may 383 have also offered historic low salinity refuge (and means of expansion) during sea-level change. 384 Thus, species likely followed the expansion and retraction of the meteoric lens vertically within 385 the Yucatán platform. Yucatán freshwater cyclopinid copepods are hypothesized to have followed 386 a similar biogeographic pattern, with southern populations migrating northward and experiencing 387 isolation events post-Pliocene ${ }^{64,65}$, however divergence times for Typhlatya species are likely due 388 to older events [4-25 Mya]. Vertebrates, such as the cave dwelling freshwater catfish, Rhamdia 
guatemalensis (Günther, 1864), show patterns consistent with colonization from the southernmost region of the northern Peninsula and subsequently expanded north and north-eastward ${ }^{66,67}$.

The precise timing and events leading to the diversification of Yucatán Typhlatya and transition to euryhaline in T. dzilamensis is difficult to discern. This study, however, reveals that present-day distributions appears to be influenced by salinity and hydrogeology. The ability of $T$. dzilamensis to cross the salinity barrier offers a great advantage to expand ecological niches and access a broader range of carbon and energy sources than previously estimated, when compared to its stenohaline counterparts ${ }^{44}$. Typhlatya dzilamensis was observed above and below the halocline within OBH (QRS) and Crustacea (QRS), and sympatric in the meteoric lens with all four species within the same system of cenotes (OBH) only a few kilometers apart, and with $T$. mitchelli in Actun Ha (Tulum, QRS). Typhlatya dzilamensis also has an extensive range from at least the north/northwestern and eastern coastal margins (> $500 \mathrm{~km})$; whereas $T$. pearsei, T. mitchelli, Typhlatya sp. A, and Typhlatya sp. B are spatially restricted to the meteoric lens of inland (YS) and coastal cenotes (QRS), $\sim 200 \mathrm{~km}$ in distance (Figure 4A). The genetic connectivity among Yucatán populations has been explored within $T$. mitchelli ${ }^{30}$, where the analysis of the fastevolving CYTB revealed low haplotypic diversity over distances of up to $235 \mathrm{~km}$. Although haplotype diversity was not measured in the current study, intra-clade pairwise genetic distances for T. mitchelli, T. pearsei and T. dzilamensis were generally less than $1 \%$ for $16 \mathrm{~S}$ and COI, respectively, thus supporting broad dispersal capabilities throughout inter-connected spelean networks of the aquifer.

\section{Implications for Continuing Integrative Research}

Biodiversity management and conservation of karst aquifers ${ }^{68}$ need more studies with an interdisciplinary research framework via the collection of integrative data (e.g., phylogeny, 
412 morphology, DNA barcoding, hydrogeology/water quality, biogeochemistry, paleoecology, 413 etc.) ${ }^{69,70}$. This study serves as a case study to provide guidance (and caution) for continuing 414 research on poorly studied stygobitic biodiversity of the Yucatán aquifer.

415 The current findings bring forth the need for revision and re-evaluation of the conservation status 416 of Typhlatya species within the Yucatán Peninsula. The Official Mexican Standards for 417 Environmental Protection (NOM-059-SEMARNAT-2010) ${ }^{23}$ lists three of four known species: $T$. 418 campecheae as federally endangered, and T. mitchelli and T. pearsei as federally threatened, while 419 IUCN Red List classifies these species as stable and of least concern ${ }^{71}$. The results unambiguously 420 showed that T. campecheae is likely not endemic to Grutas de Xtacumbilxunam (CS), nor a distinct 421 species from the vulnerable T. pearsei; thus, the endangered status should be re-evaluated. Instead, 422 our findings support an expansive distribution of T. pearsei within the meteoric lens of inland (YS 423 and CS) to coastal cenotes (QRS), with the vulnerable T. mitchelli having an overlapping range; 424 not recorded from CS cenotes (to date). Typhlatya dzilamensis is not federally listed and yet was 425 here found to be distinct from all other species, representing the only high salinity species with a 426 habitat range restricted to coastal systems throughout the Peninsula. Thus, T. dzilamensis is an 427 excellent candidate in need of evaluation, given its association with karst coastlines, which are 428 particularly vulnerable to anthropogenic impacts and coastal development changes ${ }^{68,72,73}$. Lastly, 429 the identification of two unknown species, which were 'rare' among our newly sequenced samples 430 and in previously published data, warrants further study to better understand their distributions and 431 population genetic structure. Pending species descriptions, they are likely candidates for elevated 432 conservation status.

433 The presence of Typhlatya within inland and coastal cenotes throughout the Peninsula, and their 434 strict affinity to particular salinities and hydrogeological constraints, identifies member species as 
435 potential models to assess groundwater health. Given temporal high energy meteorological events

436 (e.g., hurricanes) $)^{74}$, and other environmental impacts ${ }^{67,71,72}$, prevalent in Yucatán region and

437 continuing sea-level rise $\mathrm{e}^{58-60}$, Typhlatya species can serve as biological indicators ${ }^{75,76}$ and/or

438 indicators of ecological resilience ${ }^{77}$ to environmental change. The phylogeny presented here

439 provides a robust evolutionary hypothesis for conducting comparative studies among closely

440 related species to understand adaptation and key functional roles ${ }^{70}$. The presence of a salinity

441 generalist within coastal cave systems, like $T$. dzilamensis, provides an excellent opportunity to

442 evaluate the functional role of this adaptation in carbon-energy transfer from the meteoric lens

443 (where organic matter is abundant) to the extremely oligotrophic saline groundwater ${ }^{11}$.

444 The aforementioned would be challenging without discrete species clarity ${ }^{78}$. Therefore, the 445 Typhlatya research presented here can serve as a baseline for integrative and multi-disciplinary 446 investigations with local experts and researchers, to provide robust scientific evidence to support 447 policy, conservation efforts and biodiversity assessments of the extensive karst aquifer ecosystems 448 within the Yucatán Peninsula.

450 METHODS

$451 \quad$ Taxon sampling

452 Forty-one individuals within the genus Typhlatya were collected during several field expeditions 453 to caves throughout the Yucatán Peninsula between 2013 and 2019 (See Figure 4A; STable 2, 3). 454 Efforts were taken to collect representatives from type localities to address contentious 455 identifications, namely T. dzilamensis from Cenotes Buya-Uno, Cervera, and Dzilamway (Dzilam 456 de Bravo, YS) and T. campecheae from Grutas de Xtacumbilxunam (CS). Samples from the type 
457 locality (Grutas de Balankanche) of T. pearsei were not obtained for this study due to its status as 458 a protected archaeological site. Initial morphological identification of specimens (except from 459 specimens sampled below, OBH) followed Alvarez et al. ${ }^{25}$. Unfortunately, access to type material 460 located at the Smithsonian Institution National Museum of Natural History is not currently possible 461 due to COVID-19 restrictions.

462 Additionally, collections of Typhlatya were conducted from four caves (Na'ach Wennen Ha, 463 Odyssey, Jailhouse, Bang) within the OBH system (QRS) along a geographic transect from the 464 Caribbean coast (Figures 3B, 3C), as first described by Alvarez et al. ${ }^{25}$. Specimens were also 465 collected from Cenote Crustacea (QRS) and the Dzilam de Bravo (type locality of T. dzilamensis). 466 Specimens from these sites were collected "blindly" (i.e., without identifying to species prior to 467 preservation or sequencing) only making note of the environmental conditions (salinity, 468 temperature, depth) within cave sections of specimen collection. Individuals were collected by 469 cave divers using sampling bottles. Sampling depth and salinity were measured when possible, 470 using either YSI XLM-600, EXO-02, Hydrolab DSS, or SonTek CastAway CTD devices. Salinity 471 concentrations were classified as followed: Low salinity [0.5-4.9 psu], oligohaline meteoric lens 472 and generally above primary halocline, and High salinity [5-37 psu], mesohaline to polyhaline 473 groundwater and generally below the primary halocline; although, we recognize that these are not 474 discrete and some species may exhibit overlap between salinity designation (e.g., T. dzilamensis). 475 These designations are based on collection of specimens of this study and simplified from previous 476 salinity classifications ${ }^{79}$. The primary halocline is recognized as the mixing zone below the 477 meteoric lens, where salinity levels can be mesohaline (e.g., Casa Cenote, near Tulum, QRS) to 478 euhaline ( $>30$ psu; e.g., Giant Cave, Belize). However, salinities above five psu were not observed 479 within the meteoric lens of collection sites in this study. Salinities below the halocline were 
480 variable (and may include multiple haloclines), ranging from mesohaline (5-8 psu) ${ }^{79}$ to saline $(>30$

$481 \mathrm{psu})^{79}$. Specimens and associated salinities are indicated in Figure 3B and STable 2. Within six

482 hours of collection from the $\mathrm{OBH}$ transect, specimens were wrapped and stored at $0{ }^{\circ} \mathrm{C}$ in prebaked

$483\left(450{ }^{\circ} \mathrm{C}\right.$ for $\left.4 \mathrm{~h}\right)$ aluminum foil. The specimens were transported frozen on dry ice, and then stored

484 in the laboratory at $-20^{\circ} \mathrm{C}$. While frozen, select specimens were subsampled (i.e., abdomen) for

485 molecular analysis and transferred to $95-100 \%$ ethanol, with the remaining portion being used for

486 stable isotope and fatty acid analyses ${ }^{11}$. Other collected material was fixed in ethanol (90-100\%)

487 immediately, or frozen with liquid Nitrogen or dry ice, and stored at $-20^{\circ} \mathrm{C}$ or $-80^{\circ} \mathrm{C}$ until ready for 488 DNA extraction. Morphological and molecular vouchers are deposited at the Collection of 489 Crustacea, UNAM-Sisal, Yucatan, MX (XXXXX-XXXXX).

491 GenBank Selection, DNA Extraction

492 All available mitochondrial and nuclear gene sequences for Typhlatya species (T. pearsei, T. 493 mitchelli, T. dzilamensis, and Typhlatya sp.) from the Yucatán Peninsula were downloaded from 494 GenBank ( $\mathrm{n}=112$; STable 3). This dataset included gene fragments of mitochondrial 16S rRNA, 495 COI (two partial fragments) and CYTB, and nuclear H3, 18S rRNA, and 28S rRNA (STable 3). 496 Of all genes, 16S rRNA was one of the most consistently utilized gene across separate studies and 497 therefore represents the broadest sampling used for the phylogenetic evaluations presented here. 498 Multi-gene analyses included select individuals as clade representatives. Individual genes trees of 499 COI, CYTB, H3, 18S rRNA, and 28S rRNA are provided within the supplemental (Figs. S1-5).

500 Tissue was removed from 41 individuals and DNA was extracted following standard protocols of 501 either ethanol precipitation or the Qiagen DNeasy Tissue and Blood kit. Genes 16S rRNA, COI, 502 CYTB, H3, 18S rRNA, and 28S rRNA were amplified using primers outlined in STable 5. PCR 
503 mixtures consisted of DNA template $(1-2 \mu \mathrm{L})$, forward primer $(1 \mu \mathrm{L})$, reverse primer $(1 \mu \mathrm{L})$, water

$504(9.5 \mu \mathrm{L})$, and GoTaq ${ }^{\circledR}$ Green Mastermix $(12.5 \mu \mathrm{L})$. PCR temperature profiles are specific to each

505 primer and were run using the BIORAD T100 Thermocycler. Successful amplification was

506 observed via gel electrophoresis and purified with ExoSAP-IT PCR Product Cleanup kit. Cleaned

507 PCR products were then sent for sequencing at the Texas A\&M Corpus Christi Genomics Core

508 Lab. Geneious Prime 2020 v.2.3-2021 v.0.1 ${ }^{80}$ was used to examine, clean, and assemble raw

509 sequence data. Protein-coding genes were checked for the presence of stop-codons and

510 pseudogenes and all sequences were checked for contamination via NCBI Blast. Newly generated

511 gene data $(16 \mathrm{~S}=40 ; \mathrm{COI}=8 ; \mathrm{CYTB}=11 ; 18 \mathrm{~S}=11 ; 28 \mathrm{~S}=13 ; \mathrm{H} 3=14)$ were subsequently submitted

512 to GenBank (Accession Numbers: XXXXX-XXXXX) (STable 3).

513 Phylogenetic Analyses

514 The 16S rRNA dataset was compiled from both GenBank $(\mathrm{n}=34)$ and newly generated data $(\mathrm{n}=$ 515 40). Sixteen of the 41 newly sequenced individuals were used for our multi-gene concatenated 516 analyses (16S rRNA, COI, CYTB, H3, 18S rRNA, 28S rRNA; n=5514 bp). Individuals were 517 selected based upon their sampling locality, species identification, and sequencing success of at 518 least three of the targeted six genes. Gene alignments were concatenated using SequenceMatrix ${ }^{81}$. 519 Sequence data for each gene were aligned via MAFFT ${ }^{82}$ local iterative (18S, COI, CYTB, H3) and 520 global iterative method (16S, 28S). Phylogenetic analyses using both Maximum Likelihood (ML) 521 and Bayesian Inference (BI) were conducted on XSEDE within the CIPRES Science Gateway ${ }^{83}$. 522 Typhlatya consobrina Botoşăneanu \& Holthuis, 1970, Typhlatya garciai Chace, 1942, and 523 Typhlatya taina Estrada \& Gómez, 1987 were selected as outgroup taxa based upon previous 524 phylogenetic assessments ${ }^{22}$. Different individuals from the same outgroup species (T. taina and T. 525 consobrina) were concatenated together to provide the largest available dataset for comparison 
526 (see STable 3). JModelTest ${ }^{84}$ was utilized to select optimal substitution models for each gene based 527 upon corrected AIC for BI (see STable 6). Maximum likelihood analyses were conducted using 528 RAxML ${ }^{85}$ and node support quantified via rapid bootstrapping with 1,000 replicates. Bayesian 529 analyses were conducted using MrBayes v.3.2.7 $\mathrm{a}^{86}$ with 30 million generations, a burn-in of 10 530 million, sample frequency every 1,000 generations, and with two runs and four chains. Tracer ${ }^{87} \mathrm{v}$.

531 1.6.0 was used to confirm convergence of individual chains and examine effective sample size

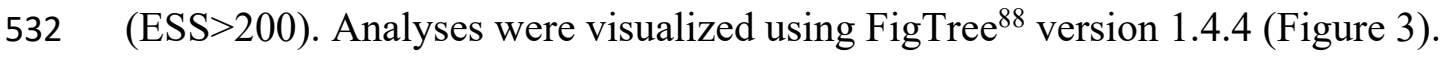

Divergence Dating

534 Divergence dating of nodes was performed using Beast ${ }^{89}$ v.2.6.3 based on the multi-gene (16S 535 rRNA, COI, CYTB, 18S rRNA, 28S rRNA, H3) dataset, with an expanded taxon sampling that included members of the Typhlatya/Stygiocaris/Typhlopatsa (TST) complex, following Jurado-

537 Rivera et al. ${ }^{22}$ Typhlatya galapagensis (Islas Isabella / Santa Cruz), Halocaridina rubra (Hawaiian 538 Islands) and Halocaridinides fowleri/H. trigonophthalma (concatenated) were included as 539 outgroup taxa, with trees rooted using $H$. fowleri/H. trigonophthalma (STable 7). Divergence 540 dating analyses used the following partitioning schemes: I) $16 \mathrm{~S}+18 \mathrm{~S} / 28 \mathrm{~S}+\mathrm{COI} / \mathrm{CYTB}+\mathrm{H} 3$ or II) $16 \mathrm{~S}+18 \mathrm{~S} / 28 \mathrm{~S}+\mathrm{COI} / \mathrm{CYTB}+\mathrm{H} 3+\mathrm{COI} / \mathrm{CYTB}$, codon $1+2$, with codon 3 excluded). 542 Each gene partitioning scheme were analyzed by enforcing the following molecular clock parameters: i) strict (partition I); ii) strict (partition II); iii) relaxed uncorrelated lognormal

544 distribution (partition I); and iv) relaxed uncorrelated lognormal distribution (partition II) and the 545 Calibrated Yule speciation model (see STable 4 for additional parameter details). Each tree used 546 the following biogeographic events as calibration points for the minimum age diversification of 547 the following TST sister taxa, following Botello et al. ${ }^{21}$ : a) isolation of T. galapagensis divergent 548 populations $(8.0 \%$ pairwise distance) on Isabella and Santa Cruz Islands, with the ancestor not 
549 older than the Coco Ridge; 5-14 Mya; b) isolation of Stygiocaris lancifera Holthuis, 1960 and 550 Stygiocaris stylifera Holthuis, 1960 ancestor post emergence of the Cape Range anticline 551 (Australia); 7-10 Mya and c) isolation of the T. consobrina + T. taina ancestor post Havana552 Matanzas Channel closure (Cuba); 5-6 Mya. Additionally, the approximate age for the 553 diversification of Halocaridina rubra Hawaiian complex ${ }^{56}$ was also included based on minimum 554 ages of their presence on the islands $(0.5-5 \mathrm{Mya})^{90}$, but does not estimate the age of the origin of 555 the species, which is much older. Site models for each partition used empirical gamma shape, 556 proportion of invariable sites and substitution rates were estimated via BIC using JModeltest.

557 Substitution rates were estimated and assumed independent among partitions and clock models 558 and tree priors were linked. Two independent runs for each clock model + partition scheme were 559 performed for 30 million generations and sampling every 1000 generations. Outputs from each 560 independent run (.log and trees files) were combined using $\log C_{\text {Combiner }}{ }^{89}$ v.2.6.3, excluding the 561 initial $10 \%$ of the burn-in, checked for convergence using $\operatorname{Tracer}^{87}$ v.1.4.4 and trees were 562 summarized using TreeAnnotator ${ }^{89}$ v.2.6.3.

Stochastic Mapping of Salinity Preference

564 Ecological transition of salinity preference within anchialine Atyidae was reconstructed via 565 stochastic mapping over the ultrametric tree from divergence dating analyses (above) and used 566 phytools $^{91}$, ape ${ }^{92}$, and geiger ${ }^{32}$ packages within R Studio ${ }^{94}$. Salinity data was compiled from the 567 literature and observations from the present study (see STable 2, 7). Salinity values were split into 568 two discrete characters: (1) low salinity tolerance [0.5-5 psu] and (2) high salinity tolerance [5-37 569 psu]. To determine whether salinity states have transitioned at equal or unequal rates, both models 570 were compared using the AIC. Software SIMMAP ${ }^{95}$ was used assuming equal rates, an equal 
571 estimation at the root, with 100 simulations on the summarized ultrametric tree. Simulations were

572 combined to visualize the probability density of each discrete character (Figure 5).

573

574

575

576

577

578

579

580

581

582

583

584

585

586

587

588

589

590

591

592

593

594

595

596

597

598

599

600

601

602

603

\section{Map Construction}

The distribution of 85 individuals of Typhlatya within the Yucatán Peninsula was visualized using software program QGIS v.3.196. Of which, 44 locality records were obtained from previous studies $^{21,22,29-34}$ and 41 records are newly generated from this study. Species identities were assigned from the single-gene phylogenies of the present study (above). Vector map data was obtained from Natural Earth (www.naturalearthdata.com). Cenotes of the type locality of $T$. dzilamensis (Dzilam de Bravo, Cervera) were treated as one locality.

\section{REFERENCES}

1. Bauer-Gottwein, P. et al. Review: The Yucatán Peninsula karst aquifer, Mexico. Hydrogeology Journal 19, 507-524 (2011).

2. Back, W., Hanshaw, B. B., Herman, J. S. \& van Driel, J. N. Differential dissolution of a Pleistocene reef in the ground-water mixing zone of coastal Yucatan, Mexico. Geology 14, 137-140 (1986).

3. Coke, J. G. Underwater Caves of the Yucatan Peninsula. in Encyclopedia of Caves (Elsevier, 2019). doi:10.1016/B978-0-12-814124-3.00127-8.

4. Smart, P. L. et al. Cave development on the Caribbean coast of the Yucatan Peninsula, Quintana Roo, Mexico. in Perspectives on Karst Geomorphology, Hydrology, and Geochemistry - A Tribute Volume to Derek C. Ford and William B. White (eds. Harmon, R. S. \& Wicks, C. M.) vol. 404 (Geological Society of America, 2006).

5. Moore, W. S. The subterranean estuary: a reaction zone of ground water and sea water. Marine Chemistry 65, (1999).

6. Moore, W. S. \& Joye, S. B. Saltwater Intrusion and Submarine Groundwater Discharge: Acceleration of Biogeochemical Reactions in Changing Coastal Aquifers. Frontiers in Earth Science 9, (2021).

7. Beddows, P. A., Smart, P. L., Whitaker, F. F. \& Smith, S. L. Decoupled fresh-saline groundwater circulation of a coastal carbonate aquifer: Spatial patterns of temperature and specific electrical conductivity. Journal of Hydrology 346, 18-32 (2007).

8. Perry, E., Velazquez-Oliman, G. \& Marin, L. The Hydrogeochemistry of the Karst Aquifer System of the Northern Yucatan Peninsula, Mexico. International Geology Review 44, (2002).

9. Kovacs, S. E. et al. Hurricane Ingrid and Tropical Storm Hanna's effects on the salinity of the coastal aquifer, Quintana Roo, Mexico. Journal of Hydrology 551, (2017). 
10. Schmitter-Soto, J. J. et al. Hydrogeochemical and biological characteristics of cenotes in the Yucatan Peninsula (SE Mexico). Hydrobiologia 467, 215-228 (2002).

11. Brankovits, D. et al. Methane-and dissolved organic carbon-fueled microbial loop supports a tropical subterranean estuary ecosystem. Nature Communications 8, 1-3 (2017).

12. Bishop, R. E. et al. 'Anchialine' redefined as a subterranean estuary in a crevicular or cavernous geological setting. Journal of Crustacean Biology 35, 511-514 (2015).

13. Angyal, D., Simões, N. \& Mascaró, M. Uptaded checklist, historical overview and illustrated guide to the stygobiont Malacostraca (Arthropoda: Crustacea) species of Yucatan (Mexico). Subterranean Biology 36, 83-108 (2020).

14. Angyal, D. et al. New distribution records of subterranean crustaceans from cenotes in Yucatan (Mexico). ZooKeys 911, 21-49 (2020).

15. Álvarez, F., Iliffe, T. M., Benítez, S., Brankovits, D. \& Villalobos, J. L. New records of anchialine fauna from the Yucatan Peninsula, Mexico. Check List 11, 1-10 (2015).

16. van Hengstum, P. J., Cresswell, J. N., Milne, G. A. \& Iliffe, T. M. Development of anchialine cave habitats and karst subterranean estuaries since the last ice age. Scientific Reports 9, 1-10 (2019).

17. Holthuis, L. Caridean Shrimps found in Land-Locked Saltwater Pools at four Indo-West Pacific Localities (Sinai Peninsula, Funafuti Atoll, Maui and Hawaii Islands), with the description of one new genus and four new species. Zoologische Verhandelingen 128, 1-48 (1973).

18. Iliffe, T. M. \& Kornicker, L. S. Worldwide Diving Discoveries of Living Fossil Animals from the Depths of Anchialine and Marine Caves. Smithsonisn Contributions to the Marine Sciences 269-280 (2009) doi:10.5479/si.01960768.38.1.

19. Calderón-Gutiérrez, F. et al. Mexican anchialine fauna - With emphasis in the high biodiversity cave El Aerolito. Regional Studies in Marine Science 9, 43-55 (2017).

20. Creaser, E. P. Crustaceans from Yucatan. in The Cenotes of Yucatan. A zoological and hydrografic survey (eds. Pearse, A. S., Creaser, E. P. \& Hall, F. G.) 117-132 (Carnegie Institution of Washington, 1936).

21. Botello, A. et al. Historical biogeography and phylogeny of Typhlatya cave shrimps (Decapoda: Atyidae) based on mitochondrial and nuclear data. Journal of Biogeography 40, 594-607 (2013).

22. Jurado-Rivera, J. A. et al. Phylogenetic evidence that both ancient vicariance and dispersal have contributed to the biogeographic patterns of anchialine cave shrimps. Scientific Reports 7, 1-11 (2017).

23. SEMARNAT. Norma Oficial Mexicana NOM-059-SEMARNAT-2010, Protección ambientalEspecies nativas de México de flora y fauna silvestres-Categorías de riesgo y especificaciones para su inclusión, exclusión o cambio-Lista de especies en riesgo. Diario Oficial de la Federación. (2010).

24. Hobbs III, H. H. \& Hobbs Jr, H. H. On the Troglobitic Shrimps of the Yucatan Peninsula, Mexico (Decapoda: Atyidae and Palaemonidae). Smithsonian Contributions to Zoology 240, 1-23 (1976).

25. Álvarez, F., Iliffe, T. M. \& Villalobos, J. L. New species of the genus Typhlatya (Decapoda: Atyidae) from anchialine caves in Mexico, the Bahamas, and Honduras. Journal of Crustacean Biology 25, 81-94 (2005).

26. Chace, F. A. \& Manning, R. B. Two new caridean shrimps, one representing a new family, from marine pools on Ascension Island (Crustacea: Decapoda: Natantia). Smithsonian Contributions to Zoology (1972) doi:10.5479/si.00810282.131.

27. Buhay, J. E. \& Crandall, K. A. Taxonomic Revision of Cave Crayfish in the Genus Cambarus, Subgenus Aviticambarus (Decapoda: Cambaridae) with Descriptions of Two New Species, $C$. Speleocoopi and C. Laconensis, Endemic to Alabama, U.S.A. Journal of Crustacean Biology 29, (2009). 
28. Juan, C., Guzik, M. T., Jaume, D. \& Cooper, S. J. B. Evolution in caves: Darwin's “wrecks of ancient life" in the molecular era. Molecular Ecology 19, 3865-3880 (2010).

29. Zakšek, V., Sket, B. \& Trontelj, P. Phylogeny of the cave shrimp Troglocaris: Evidence of a young connection between Balkans and Caucasus. Molecular Phylogenetics and Evolution 42, 223-235 (2007).

30. Hunter, R. L., Webb, M. S., Iliffe, T. M. \& Alvarado Bremer, J. R. Phylogeny and historical biogeography of the cave-adapted shrimp genus Typhlatya (Atyidae) in the Caribbean Sea and western Atlantic. Journal of Biogeography 35, 65-75 (2008).

31. von Rintelen, K. et al. Drawn to the dark side: A molecular phylogeny of freshwater shrimps (Crustacea: Decapoda: Caridea: Atyidae) reveals frequent cave invasions and challenges current taxonomic hypotheses. Molecular Phylogenetics and Evolution 63, 82-96 (2012).

32. Bracken, H. D., de Grave, S. \& Felder, D. L. Phylogeny of the Infraorder Caridea Based on Mitochondrial and Nuclear Genes (Crustacea. in Decapod Crustacean Phylogenetics (eds. Martin, J. W., Crandall, K. A. \& Felder D. L.) (Taylor and Francis/CRC Press, 2009). doi:10.1201/9781420092592-c14.

33. Porter, M. L., Pérez-Losada, M. \& Crandall, K. A. Model-based multi-locus estimation of decapod phylogeny and divergence times. Molecular Phylogenetics and Evolution 37, (2005).

34. Webb, M. S. Intraspecific relationships among the stygobitic shrimp, Typhlatya mitchelli, by analyzing sequence data from mitochondrial DNA. (2003).

35. Benson, D. A., Karsch-Mizrachi, I., Lipman, D. J., Ostell, J. \& Wheeler, D. L. GenBank. Nucleic Acids Research 36, (2007).

36. Bridge, P. D., Roberts, P. J., Spooner, B. M. \& Panchal, G. On the unreliability of published DNA sequences. New Phytologist 160, (2003).

37. Fritz, U., Vargas-Ramírez, M. \& Široký, P. Phylogenetic position of Pelusios williamsi and a critique of current GenBank procedures (Reptilia: Testudines: Pelomedusidae). Amphibia-Reptilia 33, (2012).

38. Li, X. et al. Detection of Potential Problematic Cytb Gene Sequences of Fishes in GenBank. Frontiers in Genetics 9, 30 (2018).

39. Tixier, M.-S., Hernandes, F. A., Guichou, S. \& Kreiter, S. The puzzle of DNA sequences of Phytoseiidae (Acari: Mesostigmata) in the public GenBank database. Invertebrate Systematics 25, 389-406 (2011).

40. Vilgalys, R. Taxonomic misidentification in public DNA databases. New Phytologist 160, (2003).

41. Sanz, S. \& Platvoet, D. New perspectives on the evolution of the genus Typhlatya (Crustacea. Contributions to Zoology 65, (1995).

42. Kambesis, P. N. \& Coke, J. G. Overview of the Controls on Eogenetic Cave and Karst Development in Quintana Roo, Mexico. in Coastal Karst Landforms, Coastal Research Library (eds. Lace M. \& Mylroie J.) vol. 5 (Springer, Dordrecht, 2013).

43. Benítez, S., Illife, T. M., Quiroz-Martínez, B. \& Alvarez, F. How is the anchialine fauna distributed within a cave? A study of the Ox Bel Ha System, Yucatan Peninsula, Mexico. Subterranean Biology 31, 15-28 (2019).

44. Chávez-Solís, E. M., Solís, C., Simões, N. \& Mascaró, M. Distribution patterns, carbon sources and niche partitioning in cave shrimps (Atyidae: Typhlatya). Scientific Reports 10, 1-16 (2020).

45. Jugovic, J., Prevorčnik, S., Blejec, A. \& Sket, B. Morphological differentiation in the cave shrimps Troglocaris (Crustacea: Decapoda: Atyidae) of the Dinaric karst - a consequence of geographical isolation or adaptation? Journal of Zoological Systematics and Evolutionary Research 49, 185-195 (2011).

46. Sarda, F. \& Demestre, M. Shortening of the Rostrum and Rostral Variability in Aristeus antennatus (Risso, 1816) (Decapoda: Aristeidae). Journal of Crustacean Biology 9, 570-577 (1989). 
47. Ávila-García, A., Sánchez, C., Borda, E., González-Acosta, B., Huato-Soberanis, L., \& GómezGutiérrez, J. From five to one: Sandyella species (Palaemonidae) are distinct ontogenetic stages of a single species. Zoologica Scripta 46, 488-498 (2020).

48. Martin, J. W. \& Wicksten, M. K. Review and Redescription of the Freshwater Atyid Shrimp Genus Syncaris Holmes, 1900, in California. Journal of Crustacean Biology 24, (2004).

49. Chace, F. A. Jr. A new cave shrimp from Cuba. Proceedings of the New England Zoölogical Club 19, 99-102 (1942).

50. Buden, D. W. \& Fleder, D. L. Cave shrimps in the Caicos Islands. Proceedings of the Biological Society of Washington 90, 108-115 (1975).

51. van Hengstum, P. J., Reinhardt, E. G., Beddows, P. A. \& Gabriel, J. J. Environmental reconstruction of a Mexican flooded cave system: evidence for climate- forced changes to the local freshwater lens. Quaternary Science Reviews2 29, 2788-2798 (2010).

52. van Hengstum, P. J., Scott, D. B., Gröcke, D. R. \& Charette, M. A. Sea level controls sedimentation and environments in coastal caves and sinkholes. Marine Geology 286, 35-50 (2011).

53. Gabriel, J. J. et al. Palaeoenvironmental evolution of cenote Aktun Ha (Carwash) on the Yucatan Peninsula, Mexico and its response to holocene sea-level rise. Journal of Paleolimnology 42, 199213 (2009).

54. Moritsch, M. M., Pakes M. J. and Lindberg, D. R. How might sea level change affect arthropod biodiversity in anchialine caves: a comparison of Remipedia and Atyidae taxa (Arthropoda: Altocrustacea)? Organisms Diversity and Evolution (2014) 14:225-235

55. Pindell, J. L. et al. A plate-kinematic framework for models of Caribbean evolution. Tectonophysics 155, (1988).

56. Pitman III, W. C., Cande, S. C., LaBrecque, J. \& Pindell, J. L. Fragmentation of Gondwana: the separation of Africa from South America. in Biological Relationships Between Africa and South America. (ed. Goldblatt, P.) 15-34 (Yale University Press, 1993).

57. Chakrabarty, P. Systematics and historical biogeography of Greater Antillean Cichlidae. Molecular Phylogenetics and Evolution 39, 619-627 (2006).

58. Hart Jr., C. W., Manning, R. B. \& Iliffe, T. M. The fauna of Atlantic marine caves: evidence of dispersal by sea floor spreading while maintaining ties to deep waters. Proc. Biol. Soc. Wash 98, 288292 (1985).

59. Gonzalez, B. C. et al. Genetic spatial structure of an anchialine cave annelid indicates connectivity within - but not between - islands of the Great Bahama Bank. Molecular Phylogenetics and Evolution 109, (2017).

60. Craft, J. D. et al. Islands under islands: The phylogeography and evolution of Halocaridina rubra Holthuis, 1963 (Crustacean: Decapoda: Atyidae) in the Hawaiian archipelago. Limnology and Oceanography 53, (2008).

61. Sommer, M. Late Cretaceous to Miocene tectonic reconstruction of the northwestern Caribbean: regional analysis of Cuban geology. Universität Greifswald. (2009).

62. Ramos, E. L. Geological Summary of the Yucatan Peninsula. in The Gulf of Mexico and the Caribbean (eds. Nairn A. E. M. \& Stehli F. G.) (Springer US, 1975). doi:10.1007/978-1-4684-85356 . 7.

63. Gold, D. P. et al. The biostratigraphic record of Cretaceous to Paleogene tectono-eustatic relative sealevel change in Jamaica. Journal of South American Earth Sciences (2018) doi:10.1016/j.jsames.2018.06.011.

64. Suárez-Morales, E. Historical biogeography and distribution of the freshwater calanoid copepods (Crustacea: Copepoda) of the Yucatan Peninsula, Mexico. Journal of Biogeography 30, (2003). 
65. Suarez-Morales, E., Reid, J. W., Fiers, F. \& Iliffe, T. M. Historical biogeography and distribution of the freshwater cyclopine copepods (Copepoda, Cyclopoida, Cyclopinae) of the Yucatan Peninsula, Mexico. Journal of Biogeography 31, (2004).

66. Vázquez-Domínguez, E. \& Arita, H. T. The Yucatan peninsula: biogeographical history 65 million years in the making. Ecography 33, 212-219 (2010).

67. Arroyave, J., Martinez, C. M., Martínez-Oriol, F. H., Sosa, E. \& Alter, S. E. Regional-scale aquifer hydrogeology as a driver of phylogeographic structure in the Neotropical catfish Rhamdia guatemalensis (Siluriformes: Heptapteridae) from cenotes of the Yucatán Peninsula, Mexico. Freshwater Biology 66, 332-348 (2021).

68. Guimarais, M. et al. The Conservational State of Coastal Ecosystems on the Mexican Caribbean Coast: Environmental Guidelines for Their Management. Sustainability 13, (2021).

69. Hillebrand, H., H., Jacob, U., and Leslie, H. M. Integrative research perspectives on marine conservation. Philosophical Transactions of the Royal Society B, 375 (2020).

70. Price SA, Schmitz L. A promising future for integrative biodiversity research: an increased role of scale-dependency and functional biology. Philosophical Transactions of the Royal Society B, 371 (2016).

71. IUCN 2021. The IUCN Red List of Threatened Species. Version 2021-1. https://www.iucnredlist.org. (2021).

72. Kantun Manzano, C., Arcega-Cabrera, F., Derrien, M., Noreña-Barroso, E. \& Herrera-Silveira, J. Submerged groundwater discharges as source of fecal material in protected karstic coastal areas. Geofluids 2018, (2018).

73. Arcega-Cabrera, F., Velázquez-Tavera, N., Fargher, L., Derrien, M. \& Noreña-Barroso, E. Fecal sterols, seasonal variability, and probable sources along the ring of cenotes, Yucatan, Mexico. Journal of Contaminant Hydrology 168, (2014).

74. Brown, A. L., Reinhardt, E. G., van Hengstum, P. J. \& Pilarczyk, J. E. A Coastal Yucatan Sinkhole Records Intense Hurricane Events. Journal of Coastal Research 294, (2014).

75. Graillot, D., Paran, F., Bornette, G. et al. Coupling groundwater modeling and biological indicators for identifying river/aquifer exchanges. SpringerPlus 3 (2014).

76. Trishala K. Parmar, Deepak Rawtani \& Y. K. Agrawal. Bioindicators: the natural indicator of environmental pollution, Frontiers in Life Science, 9. (2016).

77. Marten Scheffer, Stephen R. Carpenter, Vasilis Dakos, Egbert H. van Nes. Generic Indicators of Ecological Resilience: Inferring the Chance of a Critical Transition. Annual Review of Ecology, Evolution, and Systematics 46 (2015).

78. Devitt, T. J., Wright, A. M., Cannatella, D. C., Hillis, D. M. Species delimitation in endangered groundwater salamanders: Implications for aquifer management and biodiversity conservation. Proceedings of the National Academy of Sciences 116 (7), (2019).

79. Montagna, P. A., Palmer, T. A. \& Pollack, J. Hydrological Changes and Estuarine Dynamics. Springerbriefs in Environmental Science. vol. 8 (Springer New York, 2013).

80. Kearse, M. et al. Geneious Basic: An integrated and extendable desktop software platform for the organization and analysis of sequence data. Bioinformatics 28, (2012).

81. Vaidya, G., Lohman, D. J. \& Meier, R. SequenceMatrix: concatenation software for the fast assembly of multi-gene datasets with character set and codon information. Cladistics 27, (2011).

82. Katoh, K. \& Toh, H. Parallelization of the MAFFT multiple sequence alignment program. Bioinformatics 26, (2010).

83. Miller, M. A., Pfeiffer, W. \& Schwartz, T. Creating the CIPRES Science Gateway for inference of large phylogenetic trees. in 2010 Gateway Computing Environments Workshop (GCE) (2010). doi:10.1109/GCE.2010.5676129. 
84. Darriba, D., Taboada, G. L., Doallo, R. \& Posada, D. jModelTest 2: more models, new heuristics and parallel computing. Nature Methods 9, (2012).

85. Stamatakis, A. RAxML version 8: a tool for phylogenetic analysis and post-analysis of large phylogenies. Bioinformatics 30, (2014).

86. Ronquist, F. et al. MrBayes 3.2: Efficient Bayesian Phylogenetic Inference and Model Choice Across a Large Model Space. Systematic Biology 61, (2012).

87. Rambaut, A., Drummond, A. J., Xie, D., Baele, G. \& Suchard, M. A. Posterior Summarization in Bayesian Phylogenetics Using Tracer 1.7. Systematic Biology 67, (2018).

88. Rambaut, A. FigTree v1.4.3 . http://tree.bio.ed.ac.uk/software/figtree/ (2009).

89. Drummond, A. J. \& Rambaut, A. BEAST: Bayesian evolutionary analysis by sampling trees. $B M C$ Evolutionary Biology 7, (2007).

90. Neall, V. E. \& Trewick, S. A. The age and origin of the Pacific islands: a geological overview. Philosophical Transactions of the Royal Society B: Biological Sciences 363, (2008).

91. Revell, L. J. phytools: an R package for phylogenetic comparative biology (and other things). Methods in Ecology and Evolution 3, (2012).

92. Paradis, E. \& Schliep, K. ape 5.0: an environment for modern phylogenetics and evolutionary analyses in R. Bioinformatics 35, (2019).

93. Pennell, M. W. et al. geiger v2.0: an expanded suite of methods for fitting macroevolutionary models to phylogenetic trees. Bioinformatics 30, (2014).

94. RStudio Team. RStudio: Integrated Development for R. RStudio. http://www.rstudio.com/ (2020).

95. Bollback, J. P. SIMMAP: Stochastic character mapping of discrete traits on phylogenies. BMC Bioinformatics 7, (2006).

96. QGIS Development Team. Open Source Geospatial Foundation Project. QGIS Geographic Information System. http://qgis.osgeo.org (2020). 
818 Data Accessibility

819 Newly obtained sequences were deposited in GenBank Repositories under accession numbers

820 listed in STables 3 and 7. All data, including phylogenetic trees and R-scripts used throughout this

821 study are publicly available on the Open Science Framework (OSF) repository (ID: XXX)

822

823 Acknowledgements

824 Special thanks to participants for collections of Typhlatya samples from Grutas de 825 Xtacumbilxunam (Dr. Dorottya Angyal (UNAM), Kay Vilchis (CEM, photographer), Michel 826 Vazquez (CEM), Erick Sosa (CEM, photographer), Robert Romero (CEM), y Don Antonio Cab 827 (guide), Tza Itza (Dr. Dorottya Angyal), Noh-Mozon (Dr. Dorottya Angyal) and Crustacea (Dr. 828 Dorottya Angyal). We also thank Fernando Calderon-Gutierrez (TAMUG) for assistance with 829 clarifying locality data for Typhlatya specimens. Financial support for this study was provided by 830 Texas A\&M-CONACYT (TI, FA), Texas A\&M University San Antonio (TAMUSA) Start-up 831 Funds (EB), TAMUSA Research Council Grant (EB), TAMUSA Summer Faculty Grant (EB), 832 TAMUSA Summer Faculty Fellowship (EB). NSF-REU/OCE: 1560242 supported AL, and 833 TAMU-Louis Stokes Alliance for Minority Participation (HRD: 1612776) supported SR, LS. This 834 material is based upon work supported by the National Science Foundation Graduate Research 835 Fellowship Program under Grant No. (M1703014). In addition, many thanks to the Cave 836 Conservancy Foundation for providing funding support for LB. Typhlatya sampling was 837 sanctioned under collection permits SEMARNAT/SGPA/DGVS 05263/14, 004471/18, 05996/19. 
840 LB, DB, ECS and EB designed this study. LB, ECS, DB, FA, TI and EB contributed to the 841 collection and preservation of samples used in this study. All sequence data collection, editing and 842 analyses, as well as phylogenetic and evolutionary reconstructions were carried out by LB and EB, 843 with assistance from BG. LB designed all figures, with contributions from DB, BG and EB. LB, 844 AL, SR, LS, ECS contributed to photo-documentation and images. Funding provided by EB, TI, 845 NS, MPM and FA. LB and EB wrote the manuscript. All authors edited and approved the final 846 draft.

847

\section{Ethics Declaration}

849 The authors declare no competing interests 
1 Table 1. Comparison of mcraAges of Yucatán and Cuba clades estimated in previous work ${ }^{21,22}$ to those of the current study. Results

2 are based on the relaxed, log-normal clock model with four gene partitions (COI+CYTB, 16S, 18S $+28 \mathrm{~S}, \mathrm{H} 3)$ and four geological

3 events as calibration points following Botello et al. ${ }^{21}$. See also STable 4 for results from all analyses.

\begin{tabular}{|c|c|c|c|c|c|c|c|c|c|}
\hline \multirow[b]{3}{*}{ Clade } & \multicolumn{3}{|c|}{ Jurado-Rivera et al., 2017} & \multicolumn{3}{|c|}{ Botello et al, 2013} & \multicolumn{3}{|c|}{ Relaxed (4 part) } \\
\hline & \multirow{2}{*}{$\frac{\text { Height }}{\text { Mean }}$} & \multicolumn{2}{|c|}{ 95\% HPD } & \multirow{2}{*}{$\frac{\text { Height }}{\text { Mean }}$} & \multicolumn{2}{|c|}{ 95\% HPD } & \multirow{2}{*}{$\frac{\text { Height }}{\text { Mean }}$} & \multicolumn{2}{|c|}{ 95\% HPD } \\
\hline & & Upper & Lower & & Upper & Lower & & Upper & Lower \\
\hline Yucatán Typhlatya & 56.50 & 70.07 & 43.11 & 14.91 & 20.22 & 9.70 & 28.12 & 38.75 & 18.23 \\
\hline Typhlatya $\mathrm{sp} . \mathrm{A}+T$. mitchelli $+T$. pearsei & -- & -- & -- & -- & -- & -- & 16.75 & 24.76 & 9.92 \\
\hline T. mitchelli $+T$. pearsei & -- & -- & -- & 4.70 & 6.90 & 2.70 & 9.01 & 14.58 & 4.32 \\
\hline T. dzilamensis + Typhlatya sp. B & 33.35 & 44.89 & 22.36 & -- & -- & -- & 16.34 & 25.39 & 8.19 \\
\hline T. garciai $+(T$. taina $+T$. consobrina $)$ & -- & -- & -- & -- & -- & -- & 30.28 & 42.94 & 18.09 \\
\hline T. taina $+T$. consobrina & 43.52 & 58.66 & 29.25 & 5.52 & 5.99 & 5.05 & 6.18 & 7.07 & 5.33 \\
\hline Cuba + Yucatán Typhlatya & -- & -- & -- & 20.12 & 26.54 & 14.24 & 35.23 & 48.65 & 23.71 \\
\hline T. garciai $+($ Cuba + Yucatán Typhlatya $)$ & 74.01 & 88.61 & 60.08 & -- & -- & -- & -- & -- & -- \\
\hline T. garciai + (Yucatán Typhlatya) & 69.29 & 82.62 & 55.40 & -- & -- & -- & -- & -- & -- \\
\hline
\end{tabular}


1 Figure 1. Select field sites and sampling of Typhlatya specimens within the Yucatán Peninsula.

2 A. Entrance to Grutas de Xtacumbilxunam (Campeche State), showing pit-style inland cenote; 3 depth $\sim 60$ meters; note replica of wooden ladder used by Mayans to access aquifer; B. Cenote 4 Noh-Mozon (inland, Yucatán State), another inland cave, and collection site of Typhlatya pearsei; 5 C. Cave diver (ECS) collection of Typhlatya mitchelli within Cenote Tza Itza (inland, Yucatán 6 State) using catch net and falcon tube; D. Post collection (by ECS) of Typhlatya campecheae 7 within Grutas de Xtacumbilxunam, type locality; E. Cave diver (ECS) emerging from freshwater 8 entrance pool within Grutas de Xtacumbilxunam; collection site of Typhlatya campecheae. 9 Images: A-D, Kay Vilchis; E. Erick Sosa 


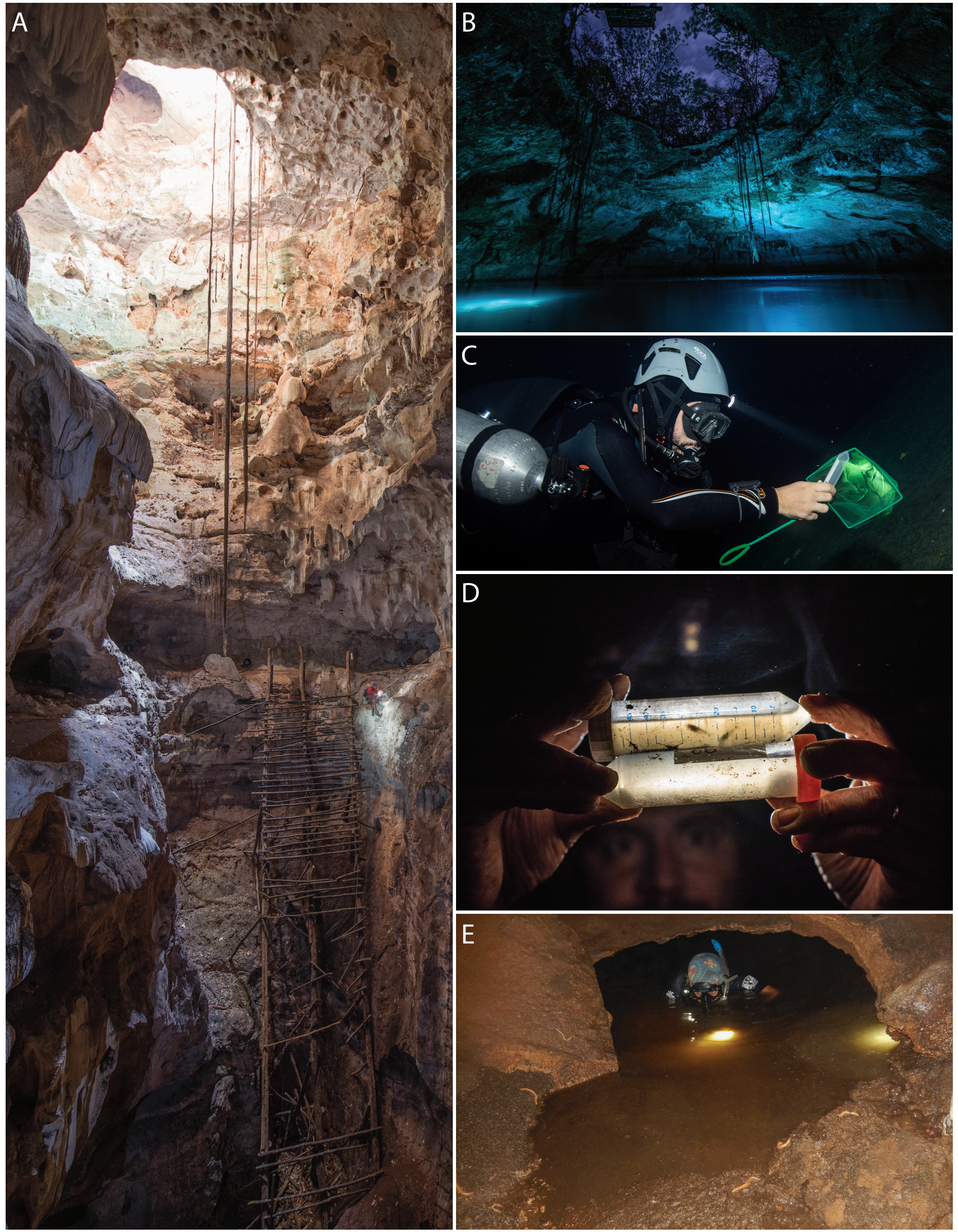


1 Figure 2. A. Graphical morphological key of Typhlatya spp. of the Yucatán Peninsula adapted 2 from Alvarez et al. ${ }^{25}$. B-E. Species of the Yucatán Peninsula. B. Typhlatya pearsei ('Ultimo 3 Suspiro', near Dzilam de Bravo); C. Typhlatya campecheae (Grutas de Xtacumbilxunam; $4 \mathrm{ID}=\mathrm{C} 2 *$ ). D. Typhlatya dzilamensis (Cenote Crustacea). D. Typhlatya mitchelli (Sistema Paamul; 5 ID=TI008D*). a, antennular peduncle; e, eyes, r, rostrum. Images taken by ECS, AL, SR, and AS. $6 \quad *$ Genetically identified in this study, Figure 3. 

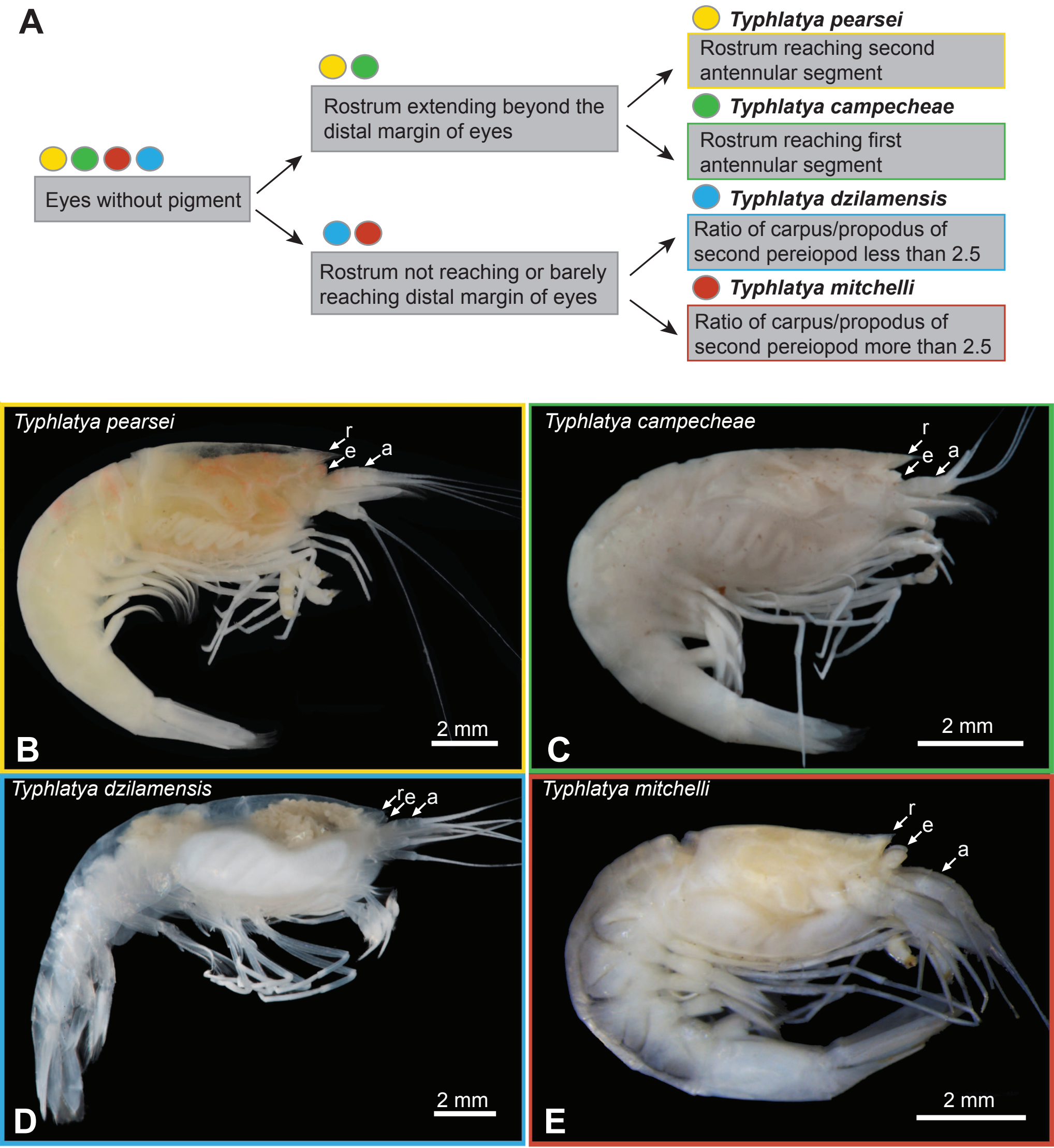

Typhlatya mitchelli

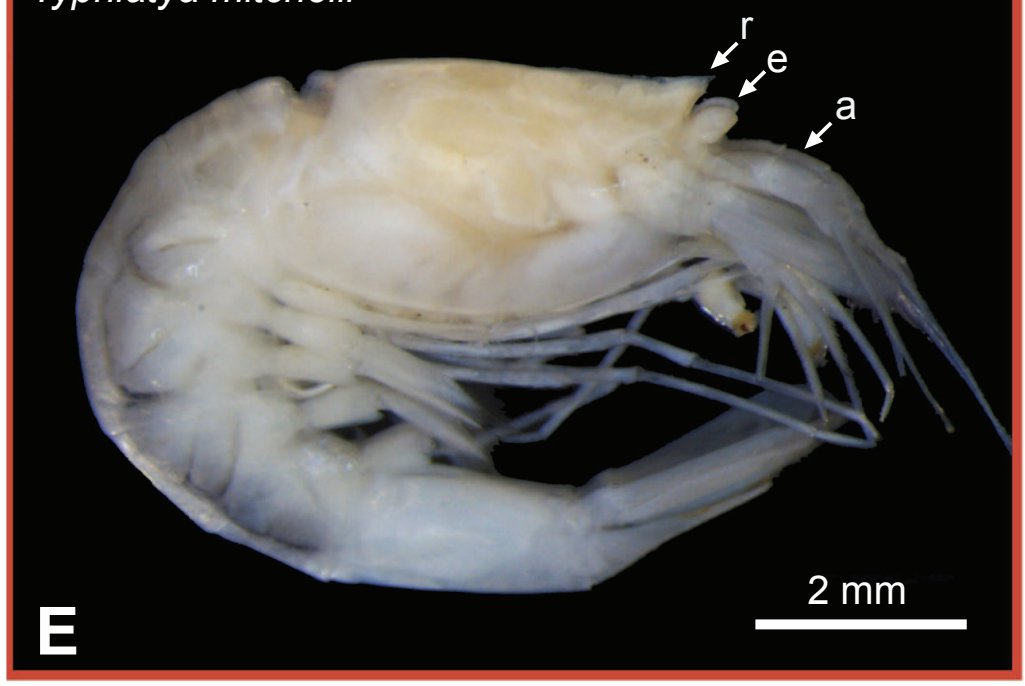


1 Figure 3. Phylogenetic hypotheses of Typhlatya spp. from the Yucatán Peninsula. A. Multi-gene 2 (16S rRNA, COI, CYTB, 18S rRNA, 28S rRNA, H3) phylogeny of select Typhlatya spp. 3 sequences, Bayesian phenogram shown. B. 16S rRNA phylogeny of GenBank and sampling new 4 to this study, Bayesian phenogram shown. C. Graphical summary of phylogenetic relationships 5 from previous studies $21,22,30,31$. Support values indicated at nodes above branches: 6 Bootstrap/Bayesian Posterior Probability. Supports values $<90 / 0.90$, not shown (see text) and 7 indicated by '-'. Colors represent species identity resulting from the molecular evaluations of the 8 study (3A-C): Typhlatya pearse $i=$ yellow, Typhlatya mitchelli $=$ red, Typhlatya dzilamensis $=$ 9 blue, Typhlatya sp. A = purple, Typhlatya sp. B = orange. Filled black shapes beside species' identifications (3B) indicate the previous identifications of GenBank material that conflict with 11 the present study: circle $=$ Typhlatya $s p$., triangle $=T$. pearsei, square $=T$. mitchelli . Shapes beside 12 species' identifications (3C) indicate all previous identifications from previous work: circle = 13 Typhlatya sp., triangle $=T$. pearsei, square $=T$. mitchelli, star $=T$. dzilamensis. Sequences from 14 specimens from type localities indicate by colored stars (A, B), green star = T. campecheae, Grutas 15 de Xtacumbilxunam; blue star $=T$. dzilamensis, Dzilam de Bravo. Sequences from samples with 16 known salinity (in psu) are indicated by colored water droplets (B), blue = low salinity, 0.5-4.99, 17 red $=$ high salinity, 5-37. 
A 16S rRNA, COI, CYTB,18S rRNA, 28S rRNA, H3

Type locality of $T$. campecheae

Type locality of $T$. dzilamensis

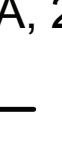

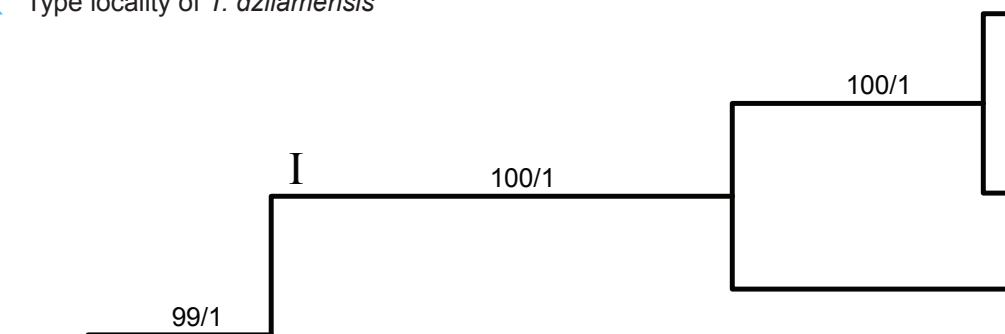

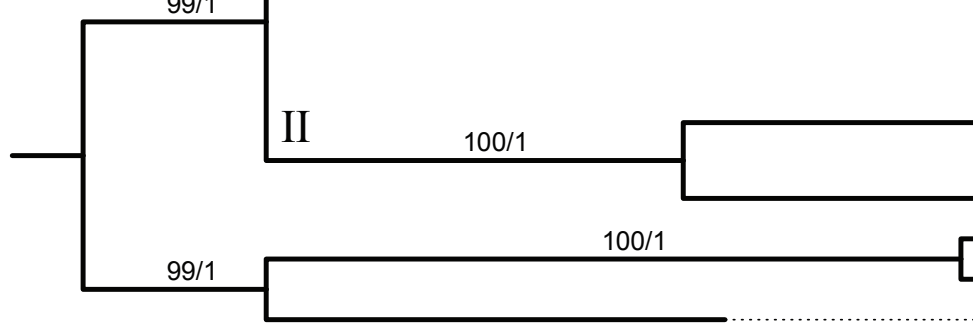

TI008B

DQ079735

HE800996

12Jailho01

AY 115541

AY 115540

AY 115544

AY115542

Typhlatya sp

- T. pearsei

T. mitchelli

$-10.98$

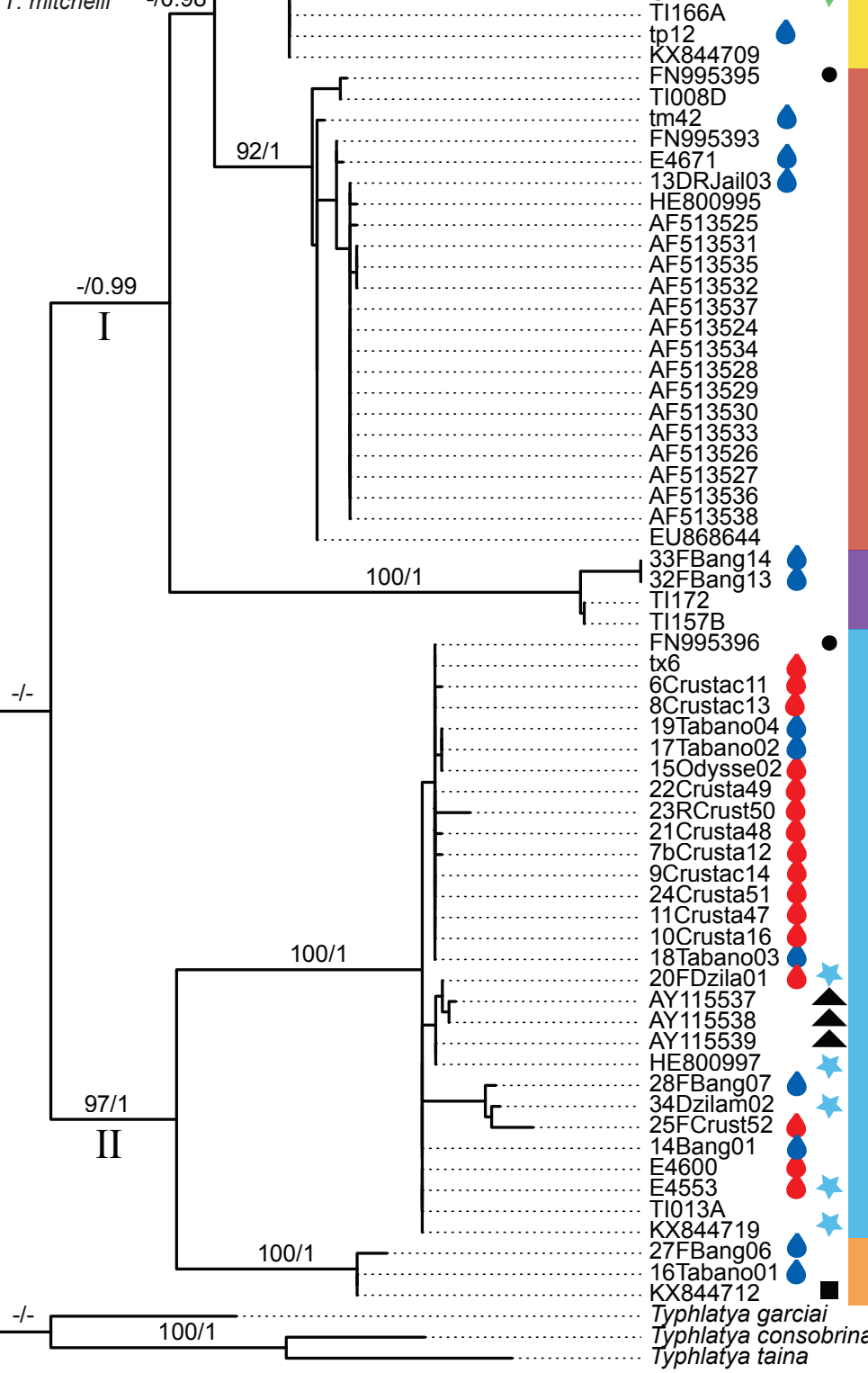

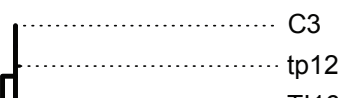

TI166A

C1

$\mathrm{C} 2$

TI008B

E4671

$\mathrm{tm} 44$

tm42

TI008D

TI157B

TI172

tx6

E4553

TI013A

E4600

KX844712

Typhlatya taina

Typhlatya consobrina

Typhlatya garciai
Typhlatya pearsei

Typhlatya mitchelli

Typhlatya

sp. A

Typhlatya dzilamensis

Typhlatya sp. B

\section{Typhlatya} mitchelli

Typhlatya sp. A

Typhlatya dzilamensis

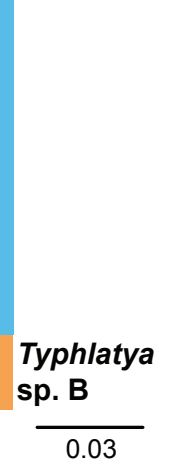

C $\square=$ T. mitchelli

$\Delta=$ T. pearsei

T. pearsei

$\mathrm{O}=$ Typhlatya sp.

Typhlatya sp. B

$\mathcal{M}=$ T. dzilamensis T. dzilamensis

Hunter et al., 2008

CYTB, $16 S$

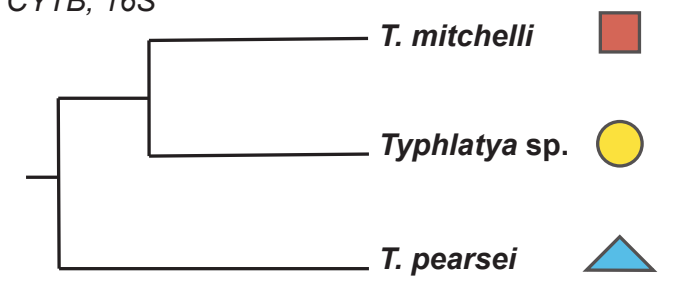

Von Rintelen et al., 2011

16S, 28S, H3

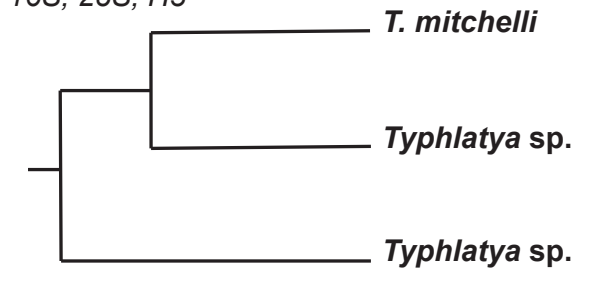

Botello et al., 2013

16S, COI, CYTB, 18S, 28S, H3

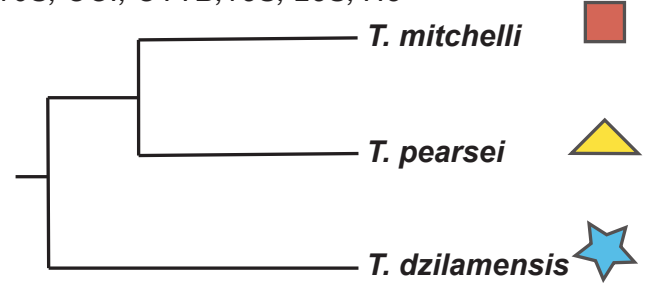

Jurado-Rivera et al., 2017

13 protein coding $\mathrm{mt}$ genes

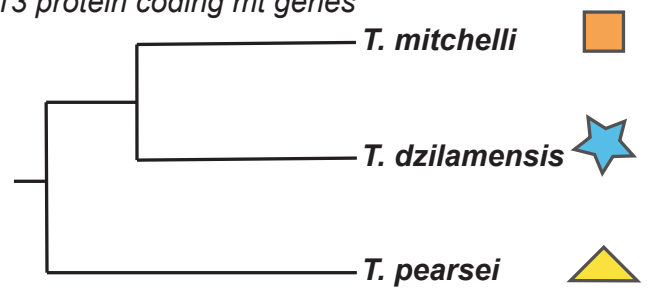


1 Figure 4. Geographic distribution of Typhlatya spp. included in this study. A. Sampling 2 distribution of Typhlatya spp. (Yucatán Peninsula); B. Sampling distribution of Typhlatya spp. 3 (Quintana Roo State, QRS); C. Hypothetical cave profile of the Ox Bel Ha system (QRS) and 4 schematic sampling distribution of the five species identified in this study, collected by salinity 5 layer. Colored symbols indicate species identification: Typhlatya pearsei $=$ yellow, triangle; $6 \quad$ Typhlatya mitchelli $=$ red, square; Typhlatya dzilamensis $=$ blue, star; Typhlatya $\mathrm{sp} . \mathrm{A}=$ purple, 7 circle; Typhlatya sp. B = orange, circle. Cave profile adapted from Brankovits et al. ${ }^{11}$. Maps were 8 made in QGIS using metadata from Natural Earth. 


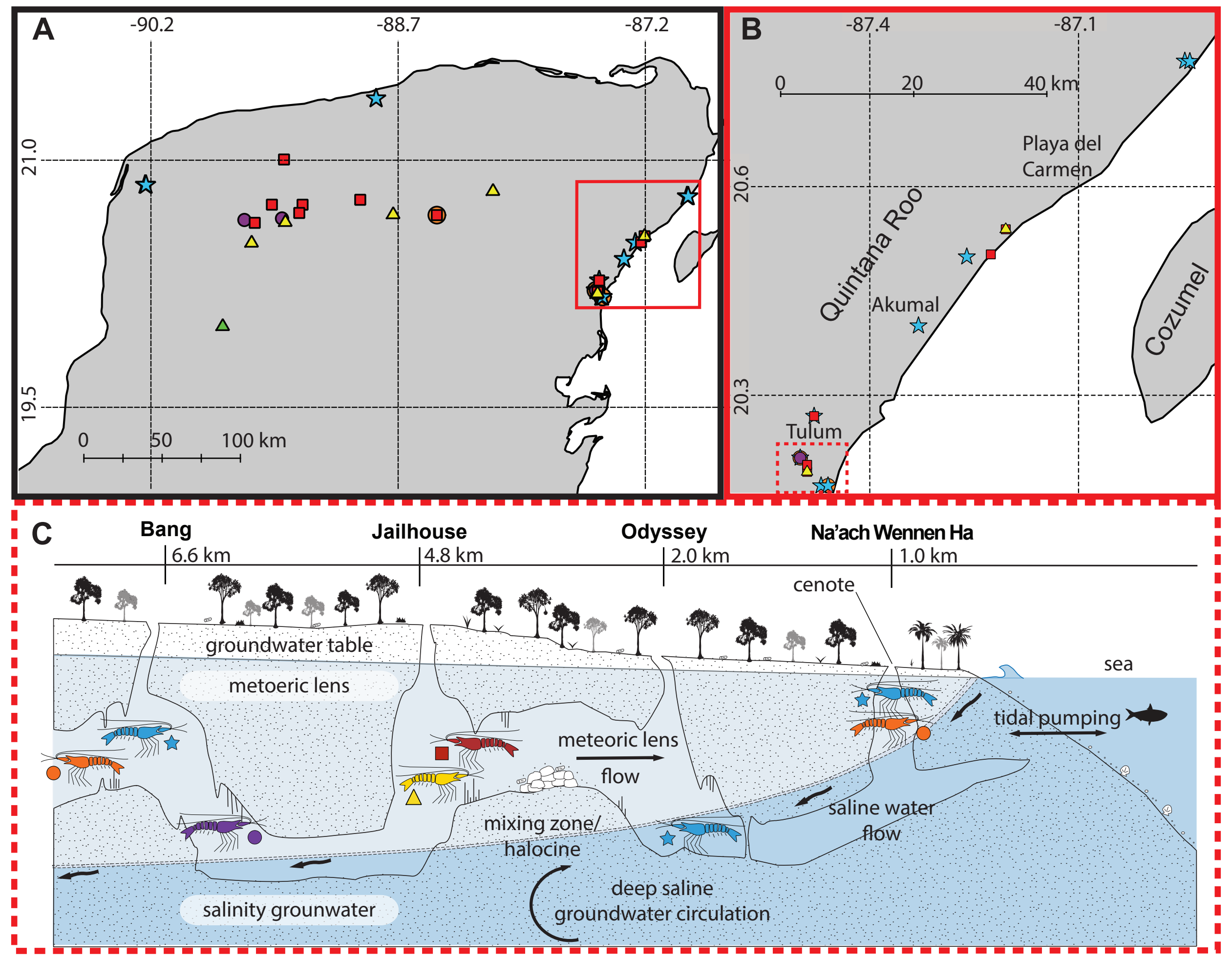


1 Figure 5. Chronogram showing divergence estimates [in brackets; Mya, 95\% high posterior 2 density limits as confidence intervals], based on a relaxed, lognormal clock, calibrated Yule model 3 and 4 gene partitions $(\mathrm{COI}+\mathrm{CYB}, 16 \mathrm{~S}, 18 \mathrm{~S}+28 \mathrm{~S}, \mathrm{H} 3)$ of the anchialine Atyidae clade. Stars at 4 nodes indicate calibration points used in analyses. Stochastic mapping of salinity trait evolution is 5 visualized with a density map overlaying the chronogram. Posterior probability (PP) of high 6 salinity/euryhaline (state $=2 ; 5-37 \mathrm{psu}$ ) is colorized, with red reflecting high PP, blue reflecting 7 low PP (and therefore, low salinity/stenohaline; 0-4.9 psu), and purple reflecting uncertainty in 8 SIMMAP analyses. 


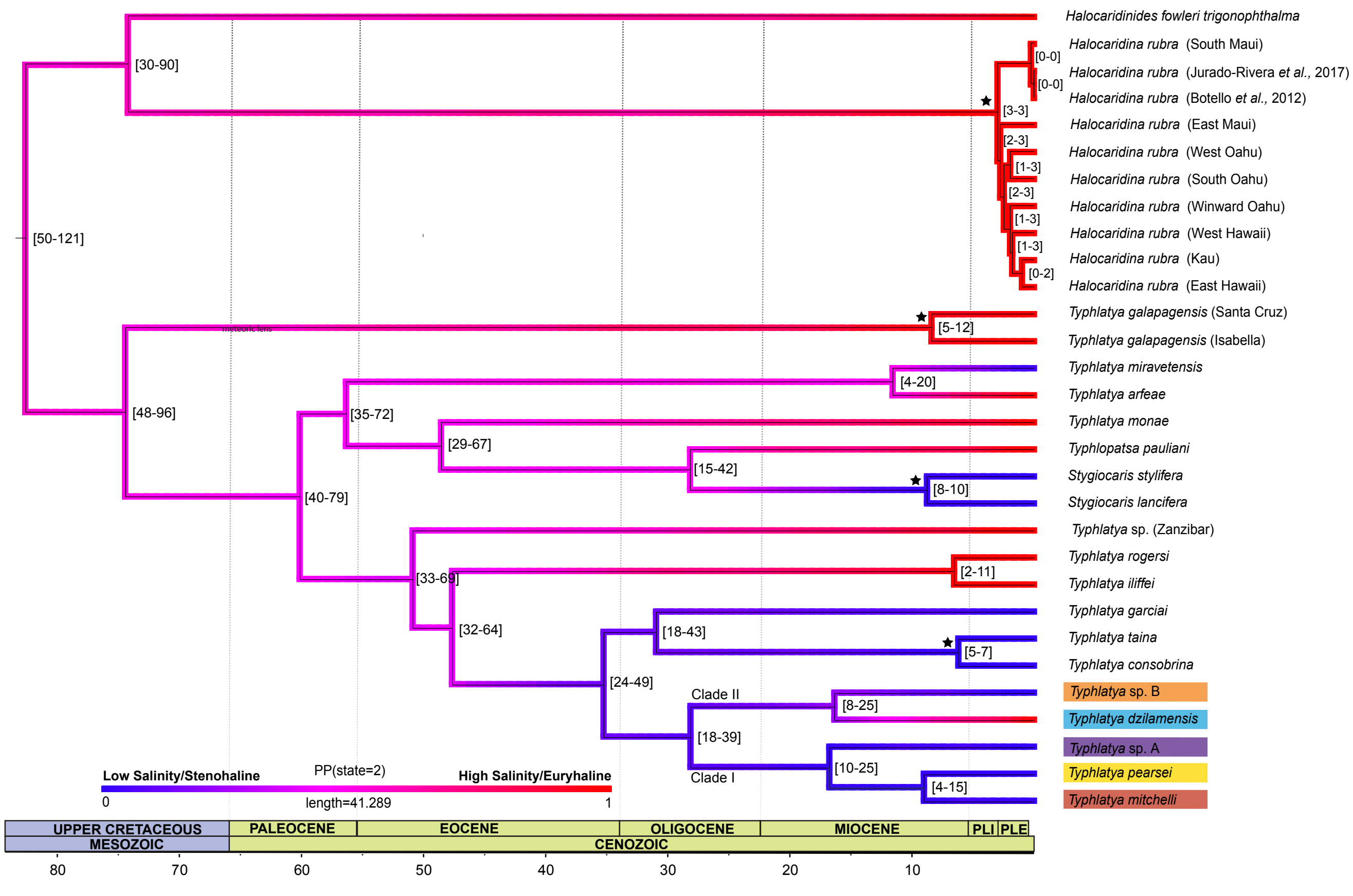




\section{Supplementary Files}

This is a list of supplementary files associated with this preprint. Click to download.

- BallouetalSuplementarylnformation26Sept.pdf 